\title{
Comparative Investigation of Non-halogenated Imidazolium and Phosphonium-based Surface-Active Ionic Liquids as Electrolyte for Supercapacitors
}

\author{
Preeti Jain, Oleg N. Antzutkin*
}

\begin{abstract}
:
We report a comparative analysis of non-halogenated surface-active ionic liquids (SAILs), which consists of the surface-active anion, 2-ethylhexyl sulfate, and the phosphonium, and imidazolium cations i.e., tetrabutylphosphonium $\left(\left[\mathrm{P}_{4444}\right]^{+}\right)$, trihexyl(tetradecyl)phosphonium $\left(\left[\mathrm{P}_{66614}\right]^{+}\right)$, and 1-methyl-3-hexylimidazolium $\left(\left[\mathrm{C}_{6} \mathrm{C}_{1} \mathrm{IM}\right]^{+}\right)$. We explored the thermal and electrochemical properties, i.e., degradation, melting and crystallization temperatures, and ionic conductivity of this new class of IL. These SAILs were tested as an electrolyte in a multiwalled carbon nanotubes (MWCNTs)-based supercapacitor at various temperatures from 253 to $373 \mathrm{~K}$. The electrochemical performance of different SAILs by varying the cationic core as a function of temperature were compared, in the same MWCNT-based supercapacitor. We found that the supercapacitor cell with $\left[\mathrm{C}_{6} \mathrm{C}_{1} \mathrm{IM}\right][\mathrm{EHS}]$ shown high specific capacitance $\left(C_{\text {elec }}\right.$ in $\left.\mathrm{F}^{-1}\right)$, a high energy density ( $E$ in $\left.\mathrm{Wh} \mathrm{kg}^{-1}\right)$, and a high power density $\left(P\right.$ in $\left.\mathrm{kW} \mathrm{kg}^{-1}\right)$ when

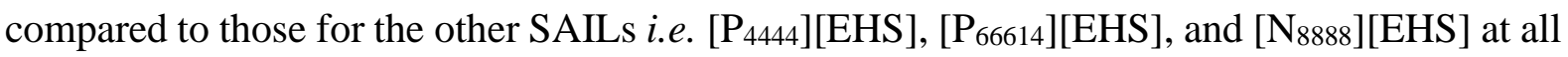
temperatures. The supercapacitor with an MWCNT-based electrode and $\left[\mathrm{C}_{6} \mathrm{C}_{1} \mathrm{IM}\right][\mathrm{EHS}]$, $\left[\mathrm{P}_{4444}\right][\mathrm{EHS}]$, and $\left[\mathrm{P}_{66614}\right][\mathrm{EHS}]$ as an electrolyte showed a specific capacitance of 148, 90, and $47 \mathrm{~F} \mathrm{~g}^{-1}$ (at the scan rate of $2 \mathrm{mV} \mathrm{s}^{-1}$ ) with an energy density of 82,50 , and $26 \mathrm{Wh} \mathrm{kg}^{-1}$ (at 2 $\mathrm{mV} \mathrm{s}^{-1}$ ) respectively, at $298 \mathrm{~K}$. The temperature effect can be seen by the three to four-fold increase in the specific capacitance of the cell and the energy density values, i.e., 290, 198, and $114 \mathrm{~F} \mathrm{~g}^{-1}$ (at $2 \mathrm{mV} \mathrm{s}^{-1}$ ) and 161, 110, and $63 \mathrm{Wh} \mathrm{kg}^{-1}\left(\right.$ at $2 \mathrm{mV} \mathrm{s}^{-1}$ ), respectively, at $373 \mathrm{~K}^{\text {. This }}$ study reveals that these new SAILs specifically $\left[\mathrm{C}_{6} \mathrm{C}_{1} \mathrm{IM}\right][\mathrm{EHS}]$ and $\left[\mathrm{P}_{4444}\right][\mathrm{EHS}]$ can potentially be used as electrolytes in the wide range of temperature. The solution resistance $\left(R_{s}\right)$, charge transfer resistance $\left(R_{c t}\right)$, and equivalent series resistance (ESR) also decreased with an increase in temperature for all SAILs as electrolytes. These new SAILs can explicitly be used for high-temperature (wide range of temperature) electrochemical applications, such as efficient supercapacitors for high energy storage due to enhanced specific capacitance, energy, and power density at elevated temperatures.
\end{abstract}

Keywords: Non-halogenated ionic liquid; Surface-active ionic liquid; Conductivity; Specific capacitance; Electric energy; Electric power density 


\section{Introduction}

Ionic liquids (ILs) have been the topic of immense interest as an electrolyte for energy storage devices due to their unique properties, such as low volatility, non-flammability, and high thermal and chemical stability, along with high electrochemical stability at high temperatures. ${ }^{1-}$ ${ }^{5}$ Among the many different ionic liquids, quaternary aprotic room temperature ILs are special due to their greater hydrophobicity and their higher thermal-electrochemical stability. ${ }^{6-8}$ The most common quaternary ionic liquids consist of ammonium or phosphonium ions with alkyl side chains. They are highly viscous and less conductive at room temperature due to the large molecular size of their cations and the formation of hydrophobically aggregated nanoscale domains. ${ }^{7-11}$ However, it can be tackled with fine-tuning the components, i.e., changing the alkyl groups on cation that make them useful in energy storage devices as electrolytes. Few studies on ammonium and phosphonium cation-based ILs with common anions like bis(trifluoromethanesulfonyl)imide, $\left[\mathrm{NTf}_{2}\right]^{-}$, or bis(fluorosulfonyl)imide, [FSI]', have shown promising performance as electrolytes with lower viscosity and a larger electrochemical potential window. However, due to their costs and presence of halides make their use limited. ${ }^{12-}$ ${ }^{14}$ The halides such as $\mathrm{Br}^{-}$and $\mathrm{F}^{-}$reduces the electrochemical stability of ionic liquids by their anodic oxidation at low potential. ${ }^{15}$

The use of ILs in supercapacitors as electrolytes or components of electrolytes is a topic of research interest. ${ }^{16}$ Supercapacitors have emerged as electrical energy storage devices and have drawn the attention of the scientific community due to their higher energy density, safety (no explosion at high temperature as happens for organic electrolytes) ${ }^{17}$, long-term stability, and high performance. The efficiency of the capacitor primarily depends on the electrode material used, and the operating potential voltage determined by the electrochemical stability window $(\mathrm{ECW})$ of the electrolyte. Intriguingly, ionic liquids exhibit interesting properties near charged surfaces that determine the performance of energy devices. In fact, recent experimental and theoretical evidence has shown the formation of an electric double layer (EDL) structure in capacitors near charged electrodes. ${ }^{18-21}$ ILs in the EDL behave differently when compared with aqueous and organic (molecular) electrolytes due to specific ion ordering in ionic liquids. ${ }^{22-24}$ Mao et al. have recently explored the electro-capacitive characteristics and EDL nanostructures of surface-active ILs (SAILs). ${ }^{18}$ SAILs can be considered as an important class of ILs since they form stable nanostructures on the hydrophobic electrode surfaces. SAILs are amphiphilic molecules with polar head groups and hydrophobic tails that enable them to form stable nanostructures, unlike non-amphiphilic ILs (NAILs). Nanostructures formed by NAILs 
are typically smaller and less stable (less ordered) than those formed by SAILs. ${ }^{18-19,} 25$ Therefore, SAILs can be used as electrolytes or components of electrolytes in supercapacitors and batteries to operate under a wider range of temperatures. ${ }^{18}$ A more thorough investigation of SAILs may increase the traditional understanding of ILs in electrochemistry. There is very little known about the SAILs and to the best of our knowledge, few studies performed on this new class of ionic liquids, which comprise a surface-active anion like 1,4-bis(2-ethylhexoxy)1,4-dioxobutane-2-sulfonate (AOT) as electrolytes in supercapacitors. ${ }^{18}$

While turning to their practical applications, the applied voltage and operating temperature range are of great importance for the construction of supercapacitor devices. High viscosity and lower ionic conductivity are typically responsible for an increase in internal resistance. The chemical structure of the ions affects the formation of the electrical double layer (EDL), which may deteriorate the capacitance of supercapacitors. Therefore, to increase the performance of supercapacitors, the wide operating potential window and a wide operating temperature interval of electrolytes is required. In addition, an appropriate selection of the chemical structure of the constituent ions is desired to enhance the interaction between the electrolyte and electrode surfaces to facilitate the formation of stable EDLs. The temperature-dependent electrode-electrolyte interactions combined with a wide operating potential window are important parameters to consider to augment the double-layer capacitance of the supercapacitors.

In the present study, we explore novel SAILs which contains surface-active anion i.e., 2ethylhexyl sulfate (EHS) and the phosphonium, and imidazolium cations i.e., tetrabutylphosphonium $\left(\left[\mathrm{P}_{4444}\right]^{+}\right)$, trihexyl(tetradecyl)phosphonium $\left(\left[\mathrm{P}_{66614}\right]^{+}\right)$, and 1-methyl3-hexylimidazolium $\left(\left[\mathrm{C}_{6} \mathrm{C}_{1} \mathrm{IM}\right]^{+}\right)$, as a potential electrolyte in supercapacitors. The EHS is an amphiphilic anion, with a polar and charged sulfate group and a non-polar and branched aliphatic group at the other end (Figure 1). Due to these distinct polar and non-polar domains, EHS-based ILs can self-assemble into nanostructures. ${ }^{26-27}$ Moreover, these non-halogenated and surface-active alkyl sulfate anions are economical and environmentally benign. These ILs are readily biodegradable compared to the other halide-containing ionic liquids, such as metal halide complexes, $\left.\left[\mathrm{PF}_{6}\right]^{-},\left[\mathrm{BF}_{4}\right]^{-}, \mathrm{NTf}_{2}\right]^{-}$and $[\mathrm{OTf}]^{-}$, which are moisture-sensitive, can easily hydrolyze, are corrosive to metals, and expensive to produce. ${ }^{2,28-30}$ Here, we studied the performance of $\left[\mathrm{P}_{4444}\right][\mathrm{EHS}],\left[\mathrm{P}_{66614}\right][\mathrm{EHS}]$, and $\left[\mathrm{C}_{6} \mathrm{C}_{1} \mathrm{IM}\right][\mathrm{EHS}]$ as electrolytes in capacitors with multi-walled carbon nanotube (MWCNT) as the electrode material at different temperatures. In the current study, MWCNT were chosen because of their specific properties, 
such as their high electrical conductivity, distinctive charge transfer capability, high electrochemical stability, high electrolyte accessibility, and double-layer capacitor behavior. ${ }^{31-}$ 34 The performance of these studied SAILs as electrolytes is also compared with the previously reported SAIL i.e., $\left[\mathrm{N}_{8888}\right][\mathrm{EHS}]$ and its binary mixtures with acetonitrile $(\mathrm{AcN})(50 \mathrm{wt} \%)$, and $6 \mathrm{M} \mathrm{KOH} \mathrm{(aq)} \mathrm{as} \mathrm{electrolytes} \mathrm{in} \mathrm{the} \mathrm{same} \mathrm{temperature} \mathrm{range.} \mathrm{We} \mathrm{showed} \mathrm{that} \mathrm{using} \mathrm{SAIL,} \mathrm{one}$ could achieve improved capacitance and a higher energy and power density at elevated temperatures up to $373 \mathrm{~K}$ with good cycling stability of the supercapacitor.

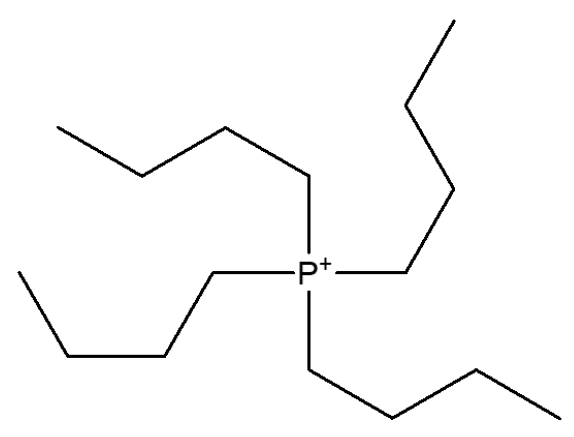

$\left[\mathbf{P}_{4444}\right]^{+}$

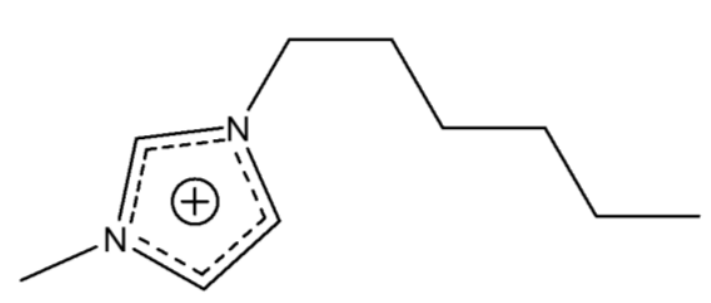

$\left[\mathrm{C}_{6} \mathrm{C}_{1} \mathrm{IM}\right]^{+}$

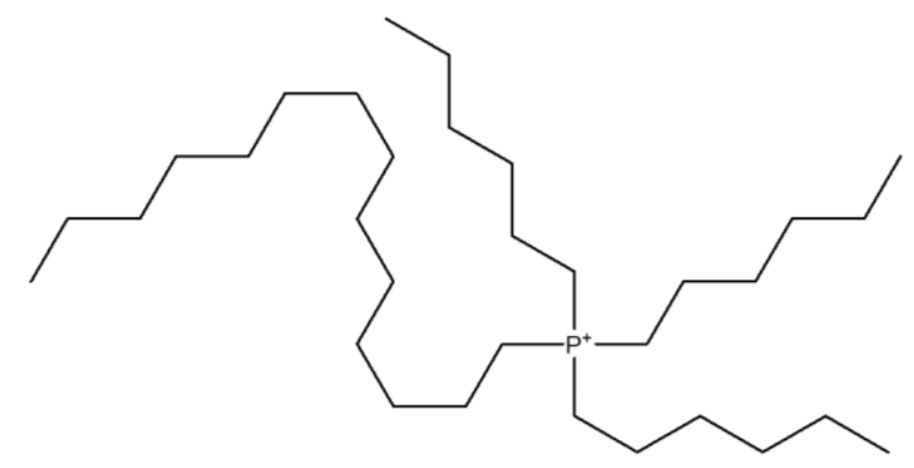

[P66614 $^{+}$

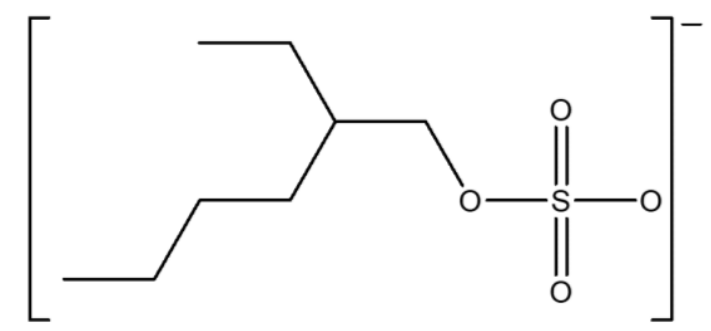

[EHS $]^{-}$

Figure 1. Chemical structure of the tetrabutylphosphonium $\left[\mathrm{P}_{4444}\right]^{+}$, trihexyl(tetradecyl)phosphonium $\left[\mathrm{P}_{66614}\right]^{+}$, and 1-methyl-3-hexylimidazolium $\left[\mathrm{C}_{6} \mathrm{C}_{1} \mathrm{IM}\right]^{+}$ cation and the 2-ethylhexyl sulfate [EHS $]^{-}$anion.

\section{Experimental Section}

\section{Chemicals and Materials}

Tetrabutylphosphonium chloride solution, $\left[\mathrm{P}_{4444}\right][\mathrm{Cl}](50 \%$ solution in water) was purchased from CYTEC, trihexyl(tetradecyl)phosphonium chloride, $\left[\mathrm{P}_{66614}\right][\mathrm{Cl}]$, 1-methyl-3hexylimidazolium bromide $\left[\mathrm{C}_{6} \mathrm{C}_{1} \mathrm{IM}\right][\mathrm{Br}]$ purchased from Solvionic, and sodium 2-ethylhexyl 
sulfate (50\% solution in water) were purchased from Sigma-Aldrich. Dichloromethane was purchased from VWR. All the materials were used as received.

For the electrode material, multi-walled carbon nanotubes (MWCNTs), activated carbon, and polyvinyl alcohol (PVA) were purchased from Sigma-Aldrich and used as received without further purification.

\section{Synthesis and Characterization of SAILs}

The final product, SAILs, $\left[\mathrm{P}_{4444}\right][\mathrm{EHS}],\left[\mathrm{P}_{66614}\right][\mathrm{EHS}]$, and $\left[\mathrm{C}_{6} \mathrm{C}_{1} \mathrm{IM}\right][\mathrm{EHS}]$ was prepared by the ion exchange reaction between the starting salt i.e. $\left[\mathrm{P}_{4444}\right][\mathrm{Cl}],\left[\mathrm{P}_{66614}\right][\mathrm{Cl}],\left[\mathrm{C}_{6} \mathrm{C}_{1} \mathrm{IM}\right][\mathrm{Br}]$ and $[\mathrm{Na}][\mathrm{EHS}]$, respectively. The metathesis reaction of the starting salts with sodium 2ethylhexyl sulfate was performed in dichloromethane (DCM) at room temperature. The SAIL was prepared by adding the sodium salt of $[\mathrm{EHS}]^{-}(1.1 \mathrm{mmol})$ to the stirred solution of starting salt $(1 \mathrm{mmol})$ in the dichloromethane (DCM). The reaction mixture was stirred for 48 hours at ambient pressure (ca. 1 bar) and at room temperature (ca. $295 \mathrm{~K}$ ). To remove the excess $[\mathrm{Na}][\mathrm{EHS}]$ salt from the final product, the reaction mixture was washed with distilled water three times. The excess DCM was removed using a rotary evaporator. To further remove traces of DCM, SAILs were kept in a vacuum oven at $353 \mathrm{~K}$ for 4 days. The purity of the prepared SAILs was checked by solution ${ }^{1} \mathrm{H},{ }^{31} \mathrm{P}$, and ${ }^{13} \mathrm{C}$ NMR spectroscopy. Traces (at the 50-500 ppm level) of the $\mathrm{Br}^{-}, \mathrm{Cl}^{-}$and $\mathrm{Na}^{+}$ions were analyzed by Inductive Coupled Plasma Atomic Emission Spectroscopy (ICP-AES) using an instrument by ALS Scandinavia, Luleå. (NMR spectra (Figure S1-S8) and results of the elemental analysis (Table S1) are provided in the Electronic Supplementary Information [ESI]).

\section{Nuclear Magnetic Resonance (NMR) Spectroscopy}

Solution ${ }^{1} \mathrm{H},{ }^{31} \mathrm{P}$, and ${ }^{13} \mathrm{C}$ spectra of SAILs (in $\mathrm{CDCl}_{3}$ with $0.03 \%$ v/v TMS) were obtained on a Brucker Avance III NMR spectrometer (Bruker BioSpin AG, Fällanden, Switzerland) with an Aeon 9.4 T zero-helium boil-off superconducting magnet using 10 and $5 \mathrm{~mm}$ probes for liquids. Working frequencies were $400.27 \mathrm{MHz}$ for ${ }^{1} \mathrm{H}, 100.64 \mathrm{MHz}$ for ${ }^{13} \mathrm{C}$, and $162.000 \mathrm{MHz}$ for ${ }^{31} \mathrm{P}$. Proton decoupling pulse sequence WALTZ-16 was used for ${ }^{13} \mathrm{C}$ NMR. For ${ }^{1} \mathrm{H} \pi / 2$ pulse duration and the recycling time was $9 \mu$ s and $1 \mathrm{~s}$, respectively. For ${ }^{31} \mathrm{P} \_$pulse duration and the recycling time was XX $\mu$ s and XXs, respectively. For ${ }^{13} \mathrm{C}, \pi / 6\left(30^{\circ}\right)$ pulse duration of $9 \mu \mathrm{s}$ and a recycling time $3 \mathrm{~s}$ was used to minimize the signal saturation effects due to the longer $\mathrm{T} 1$ relaxation time ${ }^{13} \mathrm{C}$ sites. Brucker "Topspin-3.5" software was used for NMR data processing. 


\section{Thermogravimetric analysis (TGA)}

TGA was performed using a Perkin Elmer TGA 8000 machine with about 3 mg of SAIL sample from $303 \mathrm{~K}$ to $973 \mathrm{~K}$ at a rate of $10 \mathrm{~K} \mathrm{~min}^{-1}$ under nitrogen.

\section{Differential Scanning Calorimeter (DSC)}

A Perkin Elmer DSC 6000 instrument was used to measure the melting, crystallization, and glass transition temperature of all SAILs. For these experiments, about $4 \mathrm{mg}$ of the SAIL sample was packed in an aluminium pan and heating/cooling DSC scans were recorded from 213 to $373 \mathrm{~K}$ at rates of $10 \mathrm{~K} \mathrm{~min}^{-1}$ for all SAILs. To maintain a dry environment inside the sample chamber, nitrogen gas was supplied at a flow of $20 \mathrm{~mL} \mathrm{~min}^{-1}$.

\section{Pellet Formation}

A stainless-steel pellet die was used for pellet formation. The electrode used for the current study mainly contains the MWCNTs, activated carbon, and PVA as a binder in a 7:2:1 ratio by weight, respectively. A powder composed of these three compounds was carefully mixed using a pestle and a mortar. Then pellets were pressed at varying pressures $(300-1000 \mathrm{kPa})$ by a manual press. Glass microfiber Whatman filter paper was used as a separator.

\section{Electrochemical Measurements}

All electrochemical measurements were taken using a Metrohm Autolab (PGSTAT302N) electrochemical workstation, with the FRA32M module for impedance measurements. The conductivity of the electrolytes used in this study, i.e., neat $\left[\mathrm{P}_{4444}\right][\mathrm{EHS}],\left[\mathrm{P}_{66614}\right][\mathrm{EHS}]$, and $\left[\mathrm{C}_{6} \mathrm{C}_{1} \mathrm{IM}\right][\mathrm{EHS}]$, were measured using ca. $70 \mu \mathrm{L}$ of the electrolyte solution in a TSC 70 closed cell (RHD instruments) in the temperature range between 253 and $373 \mathrm{~K}$. The supercapacitor measurements were carried out in a TSC battery cell. The cells were mounted on the Microcell HC stand with a Peltier element to control the temperature of the sample with the precision of $\pm 1 \mathrm{~K}$ in the temperature range from 269 to $373 \mathrm{~K}$ for all measurements. Prior to each experiment, the electrodes were polished using a Kemet diamond paste $(0.25 \mu \mathrm{m})$. For data processing, Nova 2.1.4 software was used. The electrochemical potential windows (ECW) for the studied SAILs were determined by cyclic voltammetry (CV) at $293 \mathrm{~K}$ using a two-electrode cell assembly with a glassy carbon working electrode and a platinum cup as the counter electrode at $100 \mathrm{mV} \mathrm{s}^{-1} \mathrm{scan}$ rate. This two-electrode cell assembly was also used to measure the ionic conductivity by electrochemical impedance spectroscopy (EIS). All EIS experiments were performed in the frequency range from $0.01 \mathrm{~Hz}$ to $1 \mathrm{M} \mathrm{Hz}$ with an alternating current (AC) 
amplitude of $10 \mathrm{mV}$. The cell was thermally equilibrated prior to each measurement for at least $10 \mathrm{~min}$.

An MWCNT-supercapacitor device was used containing two pellets (mass of each pellet was $10 \mathrm{mg}$ ) with a filter paper sandwiched between them as a separator (see Figure 2). The filter paper was kept in the electrolytes for 24 hours before measurements were taken. Pellets were $10 \mathrm{~mm}$ in diameter with an active surface of $8 \mathrm{~mm}$ in diameter (the TSC battery cell) and a glass microfiber Whatman filter paper of $12 \mathrm{~mm}$ in diameter used as a separator. The cell consists of nickel-plated copper lower and upper current collectors with an average contact area of $8 \mathrm{~mm}$ in diameter each. The cell was packed with a screw cap, and the contact pressure was adjusted with a gold-plated spring with a spring constant of $2.3 \mathrm{~N} \mathrm{~mm}^{-1}(40.7 \mathrm{kPa})$.

The electrochemical performance of the supercapacitor was measured in a two-electrode cell assembly at various temperatures. The electrochemical measurements were carried out using a TSC battery cell assembly as shown in Figure 2.

In the electrochemical tests, the supercapacitor was activated by $\mathrm{CV}$ at a lower scan rate, i.e., 50 cycles at $5 \mathrm{mV} \mathrm{s}^{-1}$ at $313 \mathrm{~K}$ for $\left[\mathrm{P}_{4444]}\right.$ [EHS] (see Figure S9) and 25 cycles at $5 \mathrm{mV} \mathrm{s}^{-1}$ at $333 \mathrm{~K}$ for $\left[\mathrm{C}_{6} \mathrm{C}_{1} \mathrm{IM}\right][\mathrm{EHS}]$ (see Figure S10). Later, electrochemical impedance spectroscopic (EIS) measurements were performed followed by CVs at different scan rates and GCD experiments. At each temperature before recording $\mathrm{CVs}$ at different scan rates, 5 cycles were recorded at $2 \mathrm{mV} \mathrm{s}^{-1}$ for further activation of the electrode. Thereafter, $\mathrm{CVs}$ were recorded at different scan rates (from 2 to $100 \mathrm{mV} \mathrm{s}^{-1}$ ) and at different temperatures interrupted by EIS measurements at each temperature. GCD tests were performed in the potential range from -2 to $+2 \mathrm{~V}$ for $\left[\mathrm{P}_{4444}\right][\mathrm{EHS}],\left[\mathrm{C}_{6} \mathrm{C}_{1} \mathrm{IM}\right][\mathrm{EHS}]$ and -2.5 to $2.5 \mathrm{~V}$ for pure $\left[\mathrm{P}_{66614}\right][\mathrm{EHS}]$ at different current densities, i.e., 0.07, 0.11, and $0.14 \mathrm{~A} \mathrm{~g}^{-1}$. The electrochemical measurements were performed for all the studied SAILs in the potential range from -2 to $+2 \mathrm{~V}(\mathrm{ECW}=4 \mathrm{~V})$. Additionally, the performance of supercapacitor cell also observed in the potential range from -2.5 to $+2.5 \mathrm{~V}(\mathrm{ECW}=5 \mathrm{~V})$ for the $\left[\mathrm{P}_{66614}\right][\mathrm{EHS}]($ at $298,313,333$, and $373 \mathrm{~K}$ ) and [P4444][EHS] (at 298 and $373 \mathrm{~K}$ )

The specific capacitance $\left(C_{\text {elec }}\right.$ in $\left.\mathrm{F} \mathrm{g} \mathrm{g}^{-1}\right)$, energy density $\left(E\right.$ in $\left.\mathrm{Wh} \mathrm{kg}^{-1}\right)$ and power density $(P$ in $\mathrm{kW} \mathrm{kg}^{-1}$ ) were calculated of the supercapacitor cell from the CV curves ${ }^{18}$ using Eqs. (1), (2) and (3), respectively as given below:

$$
C_{\text {elec }}=4 \frac{\int I d V}{m\left(\frac{d V}{d t}\right)}
$$




$$
\begin{gathered}
E=\frac{C_{s p} V^{2}}{2} \times \frac{1000}{3600} \\
P=\frac{E\left(\frac{d V}{d t}\right)}{V} \times \frac{3600}{1000}
\end{gathered}
$$

where $I$ is current (in A), $d V / d t$ is a scan rate (in $\mathrm{V} \mathrm{s}^{-1}$ ), $m$ is the total weight of the electrode material (in g), $V$ is the applied cell potential (in $\mathrm{V}$ ) and $\int I d V$ are total areas (both positive and negative but added as modulus) identified by $I(V)$ curves in the $\mathrm{CV}$ plots, and $C_{\mathrm{sp}}$ is the capacitance of the supercapacitor device $\left(C_{\mathrm{sp}}=C_{\text {elec }} / 4\right)$.

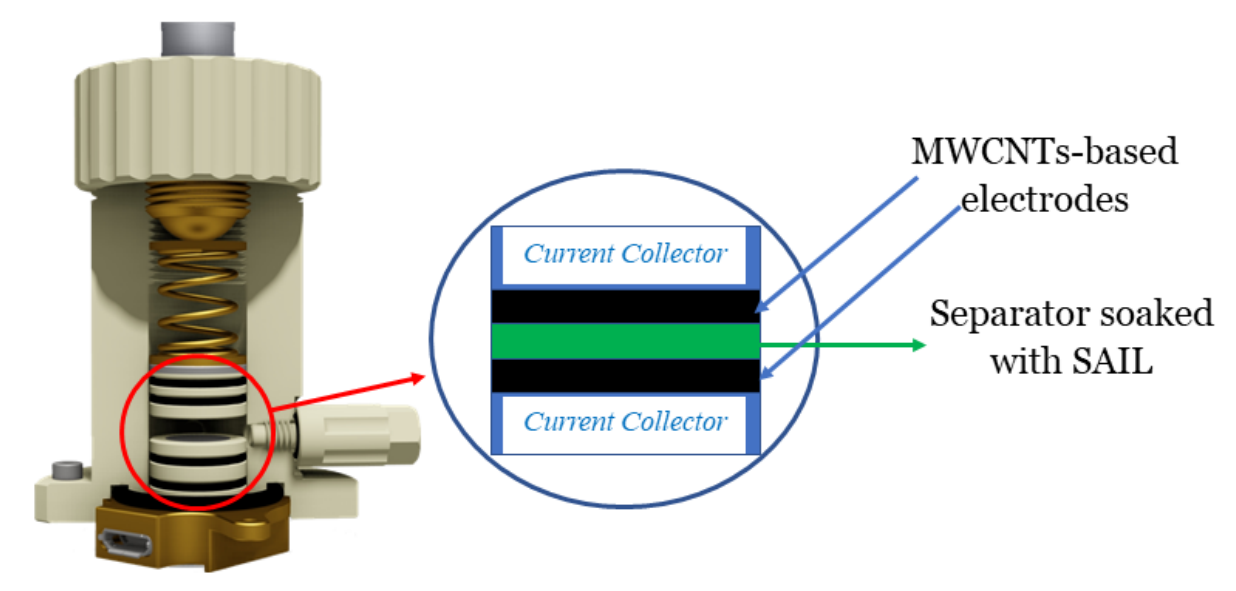

Figure 2. A setup used for the electrochemical measurements for a supercapacitor cell with MWCNT-based electrodes and $\left[\mathrm{P}_{4444}\right][\mathrm{EHS}],\left[\mathrm{C}_{6} \mathrm{C}_{1} \mathrm{IM}\right][\mathrm{EHS}]$, and $\left[\mathrm{P}_{66614}\right][\mathrm{EHS}]$, as electrolytes. The supercapacitor is yet not placed in the setup.

\section{Results and Discussion}

Conductivity and Electrochemical Potential Window of SAILs

Conductivity of ILs originates from the intrinsic motion of cations and anions. In the present study we note major impact of the cation structure on the conductivity. The ionic conductivity of neat SAILs, [P 4444$][\mathrm{EHS}],\left[\mathrm{C}_{6} \mathrm{C}_{1} \mathrm{IM}\right][\mathrm{EHS}]$, and $\left[\mathrm{P}_{66614}\right][\mathrm{EHS}]$ was measured using GCelectrodes in the temperature range from 253 to $373 \mathrm{~K}$. Measurements at each temperature point were performed in duplicate, first, during sample heating and then during cooling. The conductivity data points obtained during sample heating and cooling were close to each other (see Figure 3). The electric conductivity for the $\left[\mathrm{C}_{6} \mathrm{C}_{1} \mathrm{IM}\right][\mathrm{EHS}]$ is observed to be higher compared to the $\left[\mathrm{P}_{4444}\right][\mathrm{EHS}]$ and $\left[\mathrm{P}_{66614}\right][\mathrm{EHS}]$. At $298 \mathrm{~K}$, the value of conductivity are 73.19

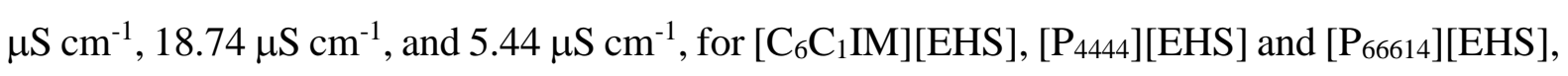


respectively and increased upto $1.62 \mathrm{mS} \mathrm{cm}^{-1}, 0.68 \mathrm{mS} \mathrm{cm}^{-1}$, and $0.15 \mathrm{mS} \mathrm{cm}^{-1}$ at $373 \mathrm{~K}$, respectively. The conductivity is mainly dependent upon the number of mobile ions available in the system. However, we note a significant difference in the conductivity values at lower temperatures as they might be forming ionic complexes due to large ion size/aggregation/ionpairing. This leads in the reduction of ion mobility and conductivity.. On the other hand, upon increasing the temperature, ion mobility increases hence conductivity values increases at the elevated temperature i.e., $373 \mathrm{~K}$. Despite low electric conductivity at ambient temperatures, this class of SAILs can be considered as better electrolyte for supercapacitors, compared to organic- and aqueous-based electrolytes due to the significantly larger ECW (Figure 4) and, thus, the larger amount of energy can be stored in these devices (see Eq. (2)): The ECW of an electrolyte plays a crucial role in the supercapacitors because the energy density of this device depends on the square of the operating electrochemical potential window. The electric conductivity for the $\left[\mathrm{C}_{6} \mathrm{C}_{1} \mathrm{IM}\right][\mathrm{EHS}]$ is around three orders of magnitude higher than that for the $\left[\mathrm{P}_{4444}\right][\mathrm{EHS}]$ and nine times of the $\left[\mathrm{P}_{66614}\right][\mathrm{EHS}]: 0.073$ and $1.62 \mathrm{mS} \mathrm{cm}^{-1}$ at 298 and 373 $\mathrm{K}$, respectively.

CVs recorded for different potential windows as shown in Figure 4 show electrochemical stability (no change in $\mathrm{CV}$ ) with applied potential up to +2 to $-2 \mathrm{~V}$ for neat SAILs. As previously reported these SAILs can be used in the potential range from -2 to $+2 \mathrm{~V}$. Interestingly, $\left[\mathrm{C}_{6} \mathrm{C}_{1} \mathrm{IM}\right][\mathrm{EHS}]$ shows some redox peaks at the higher temperatures and can contribute to the enhancement of the specific capacitance i.e., pseudocapacitance. The phosphonium-based ILs are shown to possess greater electrochemical stability as compared to the ammonium-based ILs. ${ }^{35}$ In this study, we further used $\left[\mathrm{P}_{66614}\right][\mathrm{EHS}]$ and $\left[\mathrm{P}_{4444}\right][\mathrm{EHS}]$ for the extended electrochemical potential window from $4 \mathrm{~V}(-2$ to +2$)$ to $5 \mathrm{~V}(-2.5$ to +2.5$)$.
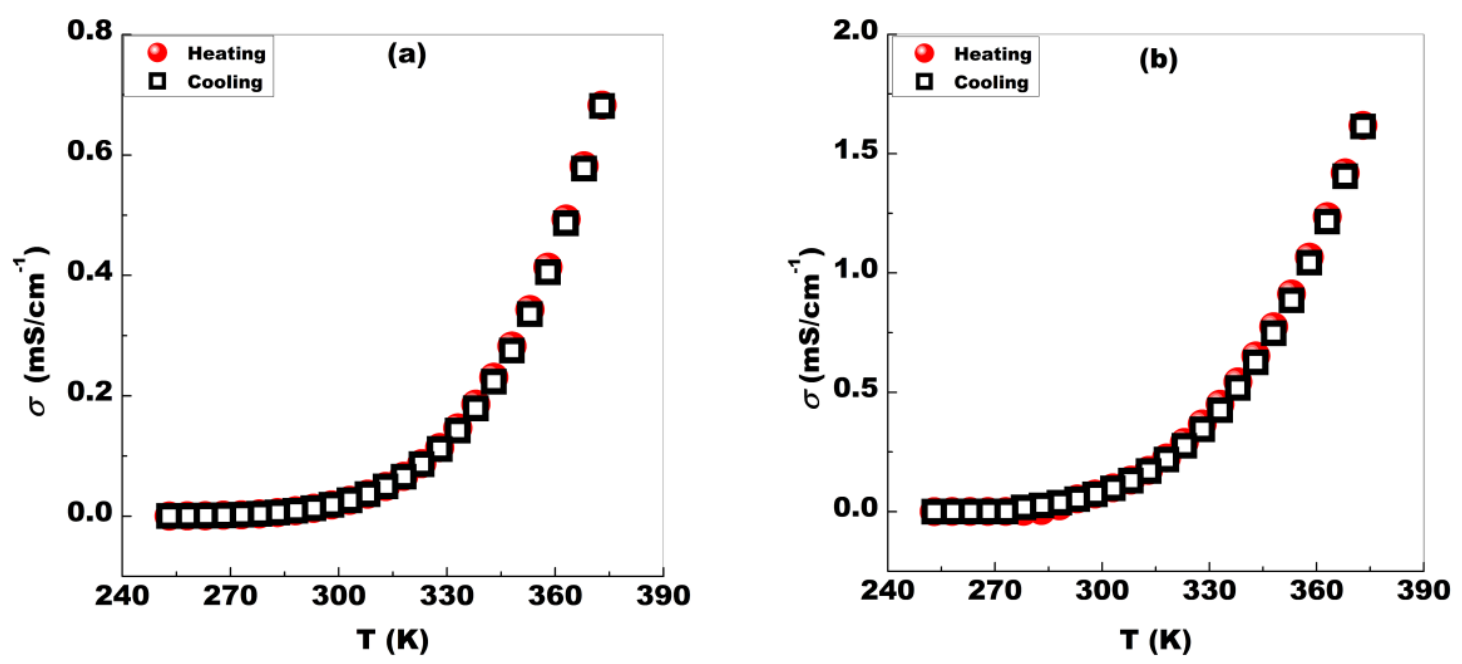


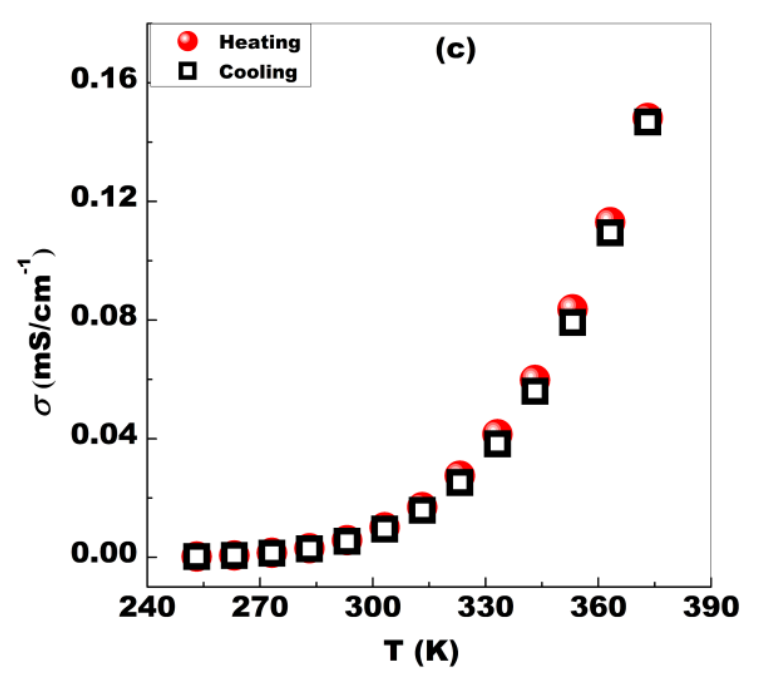

Figure 3. Comparative (heating/cooling) conductivity data of neat $\left[\mathrm{P}_{4444}\right][\mathrm{EHS}]$ (a), $\left[\mathrm{C}_{6} \mathrm{C}_{1} \mathrm{IM}\right][\mathrm{EHS}](\mathbf{b})$, and $\left[\mathrm{P}_{66614}\right][\mathrm{EHS}](\mathbf{c})$ on $\mathrm{GC}$ electrode at the amplitude of $10 \mathrm{mV}$.

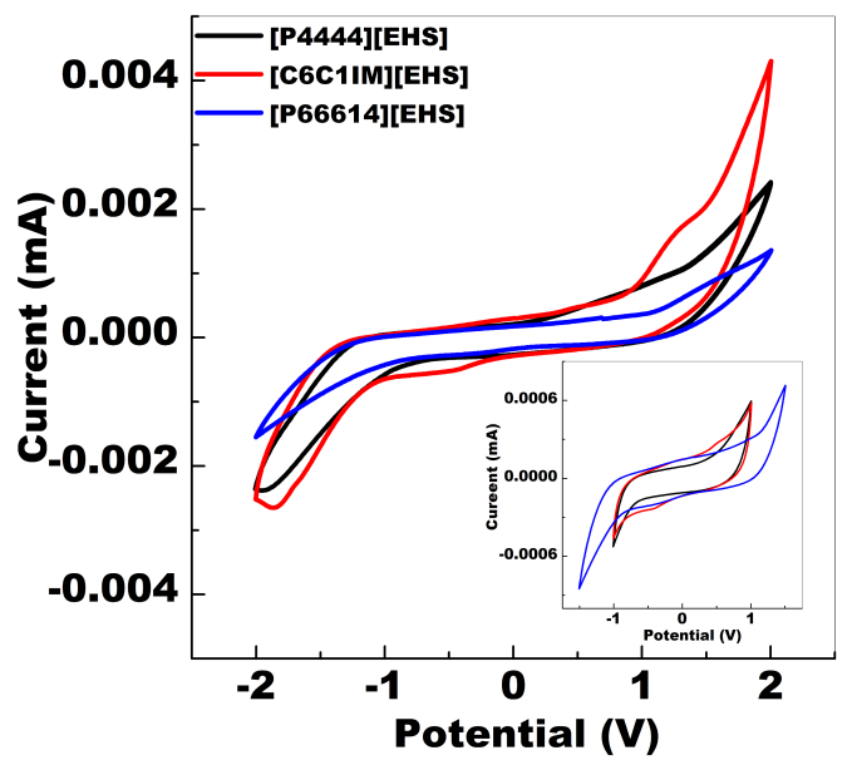

Figure 4. Electrochemical potential window on the GC electrodes for neat $\left[\mathrm{P}_{4444}\right][\mathrm{EHS}]$, $\left[\mathrm{C}_{6} \mathrm{C}_{1} \mathrm{IM}\right][\mathrm{EHS}]$, and $\left[\mathrm{P}_{66614}\right][\mathrm{EHS}]$ from -2 to $+2 \mathrm{~V}$ and inset figure shows from -1 to $+1 \mathrm{~V}$ for $\left[\mathrm{P}_{4444}\right][\mathrm{EHS}],\left[\mathrm{C}_{6} \mathrm{C}_{1} \mathrm{IM}\right][\mathrm{EHS}]$ and from -1.5 to $+1.5 \mathrm{~V}$ for $\left[\mathrm{P}_{66614}\right][\mathrm{EHS}]$.

Thermal Characterization of SAILs by DSC and TGA

The thermal stability of ILs mainly depends on the structure of constituent ions i.e., cation/anion and their interionic interations. Thermal properties of the neat SAILs were examined by thermal gravimetric analysis (TGA) and differential scanning calorimetry (DSC). 
The TG plot and DSC trace of the studied SAILs are shown in Figures 5 and 6, respectively. The decomposition temperature $\left(\mathrm{T}_{\mathrm{d}}\right)$ and melting, and crystallization, temperatures were measured by TGA and DSC, respectively. The $T_{d}$ of a given IL depends on the inherent stability of the ionic liquids and the interactions between their constituent ions. The TG plot shows decomposition of $\left[\mathrm{P}_{4444}\right][\mathrm{EHS}],\left[\mathrm{P}_{66614}\right][\mathrm{EHS}]$, and $\left[\mathrm{C}_{6} \mathrm{C}_{1} \mathrm{IM}\right][\mathrm{EHS}]$ at 587, 602, and $564 \mathrm{~K}$ (onset temperature), respectively as shown in Figure 5. This is in accordance with the other studies that have shown immidazolium-based ionic liquids are thermally less stable than the phosphonium and more stable than the ammonium-based ionic liquids. ${ }^{36}$ The differences here seen are mainly coming from the cationic part as we are using same anion. The DSC trace of $\left[\mathrm{C}_{6} \mathrm{C}_{1} \mathrm{IM}\right][\mathrm{EHS}]$ in Figure 6 shows a couple of thermal events during heating and cooling scans. During the heating cycle at $10 \mathrm{~K} \mathrm{~min}^{-1}$ from $213 \mathrm{~K}$, two thermal events can be seen occurring at $257 \mathrm{~K}$ (crystallization), and $298 \mathrm{~K}$ (melting), while for the cooling cycle, the one peak observed at $265 \mathrm{~K}$ which corresponds to the crystallization. However, the other two SAILs, shows no thermal event in the temperature range from 213 to $373 \mathrm{~K}$ as shown in Figure 6 and can be used as electrolyte in the wider range of temperature. We performed the heating and cooling ramp at $10 \mathrm{~K} \mathrm{~min}^{-1}$ and all further heating and cooling cycles are reproducible and similar to the first heating and second cooling cycles.

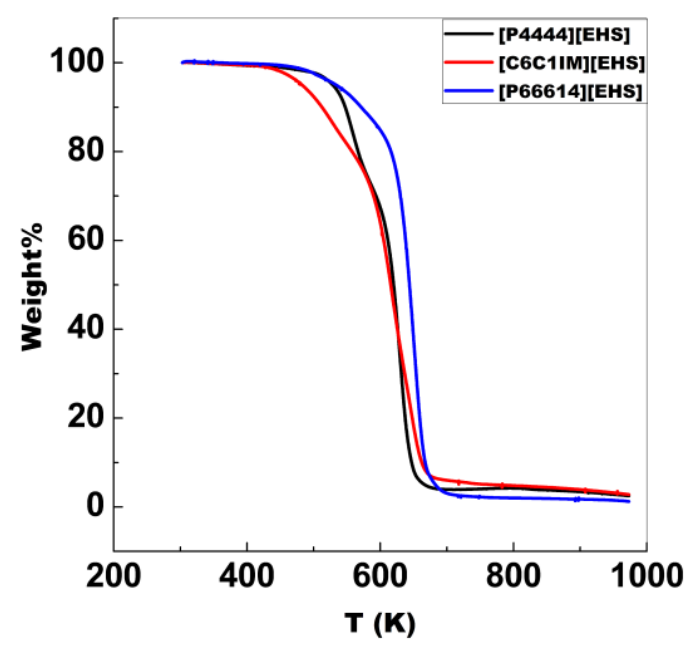

Figure 5. TG-plots of $\left[\mathrm{P}_{4444}\right][\mathrm{EHS}],\left[\mathrm{C}_{6} \mathrm{C}_{1} \mathrm{IM}\right][\mathrm{EHS}]$, and $\left[\mathrm{P}_{66614}\right][\mathrm{EHS}]$ in the temperature range from 303 to $973 \mathrm{~K}$. 


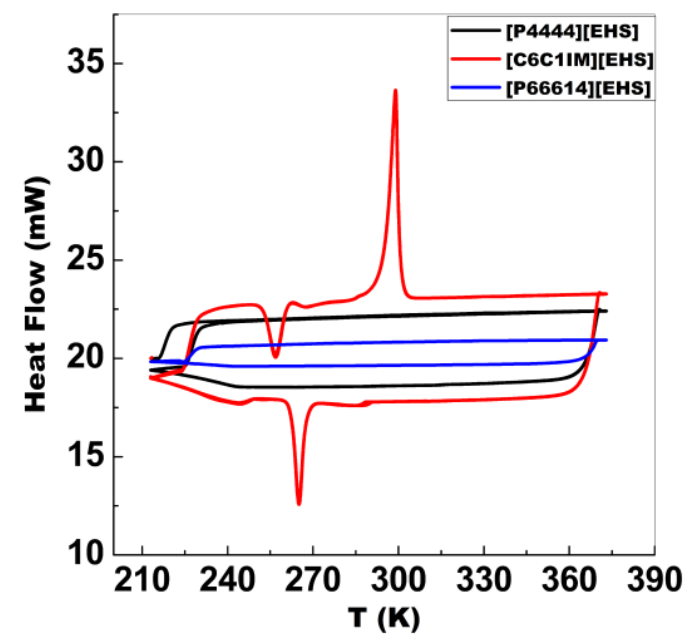

Figure 6. DSC traces for pure SAILs, $\left[\mathrm{P}_{4444}\right][\mathrm{EHS}]$ (black line), $\left[\mathrm{C}_{6} \mathrm{C}_{1} \mathrm{IM}\right][\mathrm{EHS}]$ (red line), and $\left[\mathrm{P}_{66614}\right][\mathrm{EHS}]$ (blue line) at $10 \mathrm{~K} \mathrm{~min}^{-1}$.

Therefore, the wide ECW, moderate ionic conductivity, high thermal and electrochemical stability, and surface-active anion makes these new SAILs, as promising solvent-free, environmentally benign, and economical electrolyte for the high energy storage devices such as supercapacitors.

\section{Supercapacitor Measurements}

The CV curves for the MWCNT-based electrode material and SAILs ([P4444][EHS], $\left.\left[\mathrm{C}_{6} \mathrm{C}_{1} \mathrm{IM}\right][\mathrm{EHS}],\left[\mathrm{P}_{66614}\right][\mathrm{EHS}]\right)$ as the electrolytes at different temperatures are shown in Figure S11, S12, and S13, respectively in the Electronic Supplementary Information (ESI). The rectangular shape of the $\mathrm{CV}$ at lower scan rates is noted, however, it distorts at higher scan rates, i.e., 50 and $100 \mathrm{mV} \mathrm{s}^{-1}$ at 298, 313 and $333 \mathrm{~K}$. Interestingly, for higher temperatures, i.e., 353 and $373 \mathrm{~K}$, the $\mathrm{CV}$ shows a rectangular shape even regardless of scan rates, indicates the possibility of double-layer capacitance of the MWCNT-based supercapacitor and shows the better capacitance. The change in specific capacitance $\left(C_{\text {elec }}\right)$ values with the potential scan rate at different temperatures is shown in Figure 7 for all the studied SAILs. A rectangular CV shape indicates better capacitive behavior of the capacitor at lower scan rates but poor capacitive performance at higher scan rates at 298, 313 and $333 \mathrm{~K}$. However, the capacitance improved at 353 and $373 \mathrm{~K}$ at all scan rates. The poor capacitance may be ascribed to the slower diffusion of electrolyte ions from the electrolyte to the electrodes at the lower temperatures. This indicates that SAIL shows better performance as an electrolyte at high temperatures without distorting the chemical and electrochemical stability. $\left[\mathrm{C}_{6} \mathrm{C}_{1} \mathrm{IM}\right][\mathrm{EHS}]$ shows the higher specific capacitance values as compared to the $\left[\mathrm{P}_{4444}\right][\mathrm{EHS}]$ and $\left[\mathrm{P}_{66614}\right][\mathrm{EHS}]$ shows the 
lowest values in the whole temperature range from 298 to $373 \mathrm{~K}$ with $\mathrm{ECW}=4 \mathrm{~V}$. The $\mathrm{CV}$ curves for the MWCNT-based electrode material and [P66614][EHS] as the electrolytes with the larger ECW (5V) at different temperatures are shown in Figure S14. Whereas Figure 7(d) shows the specific capacitance values for $\left[\mathrm{P}_{66614}\right][\mathrm{EHS}]$ for the enhanced ECW i.e., 5V. A significant increase in the specific capacitance values obtained for the $\left[\mathrm{P}_{66614}\right][\mathrm{EHS}]$ at $5 \mathrm{~V}$ (Figure 7(d)) as compared to the $4 \mathrm{~V}$ (Figure 7(c)) ECW. However, [P66614][EHS] may not be appropriate for MWCNT-based electrodes as the charging/discharging and capacitive behavior depends on the pore size of the electrode material and the ion size of the electrolytes. Due to its larger cation size, $\left(\left[\mathrm{P}_{66614}\right]^{+}\right)$might not get absorbed into the narrow pores of MWCNTs. ${ }^{37}$ We tried to reduce the size of the anion compared to the other studied SAIL. ${ }^{18}$ We also tried to get the better performance by reducing the size of cation too such as $\left[\mathrm{P}_{4444}\right]^{+}$and $\left[\mathrm{C}_{6} \mathrm{C}_{1} \mathrm{IM}\right]^{+}$. A significant effect of reducing size can be clearly observed for $\left[\mathrm{C}_{6} \mathrm{C}_{1} \mathrm{IM}\right][\mathrm{EHS}]$ and [P 4444$][\mathrm{EHS}]$ SAILs as electrolyte by enhanced specific capacitance, energy density, and power density values in the whole range of temperature. However, SAILs should be used with other high surface area electrodes for even better performance and more specific capacitance. ${ }^{38-41}$
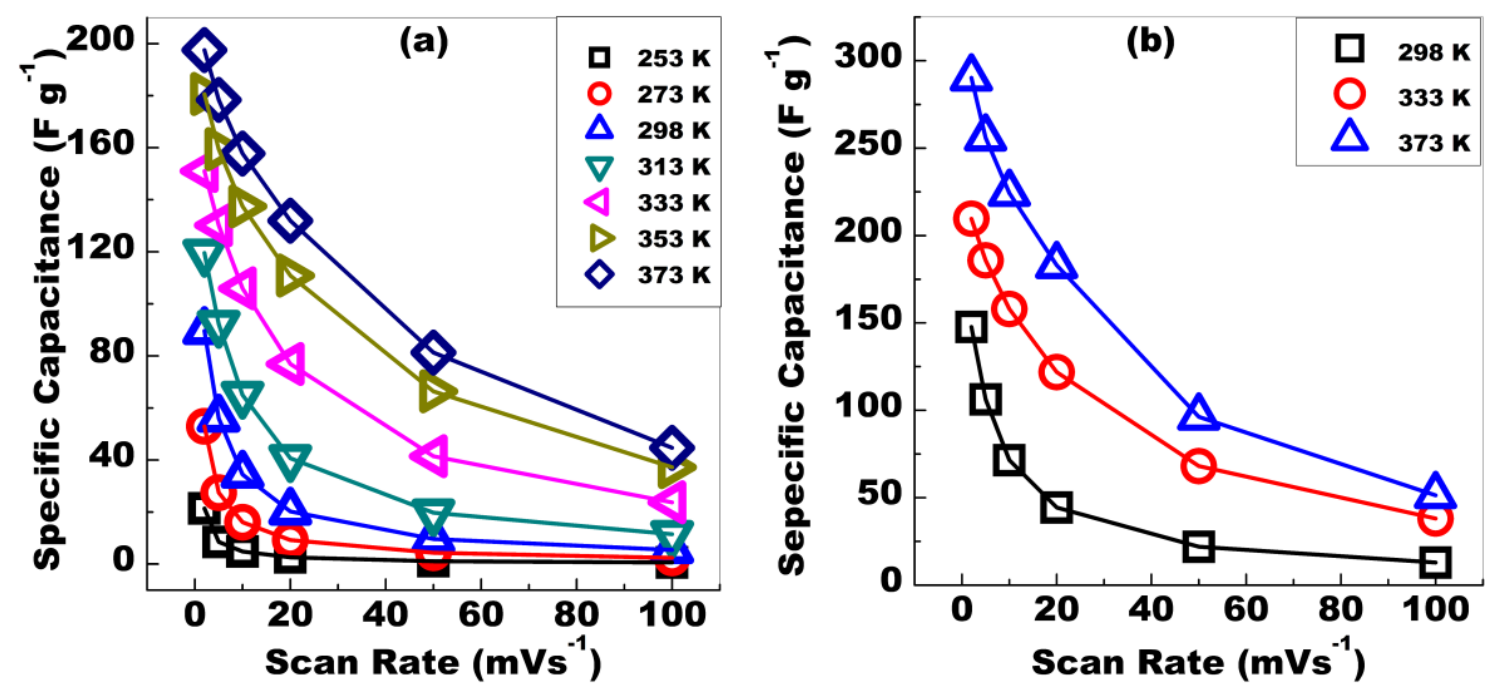

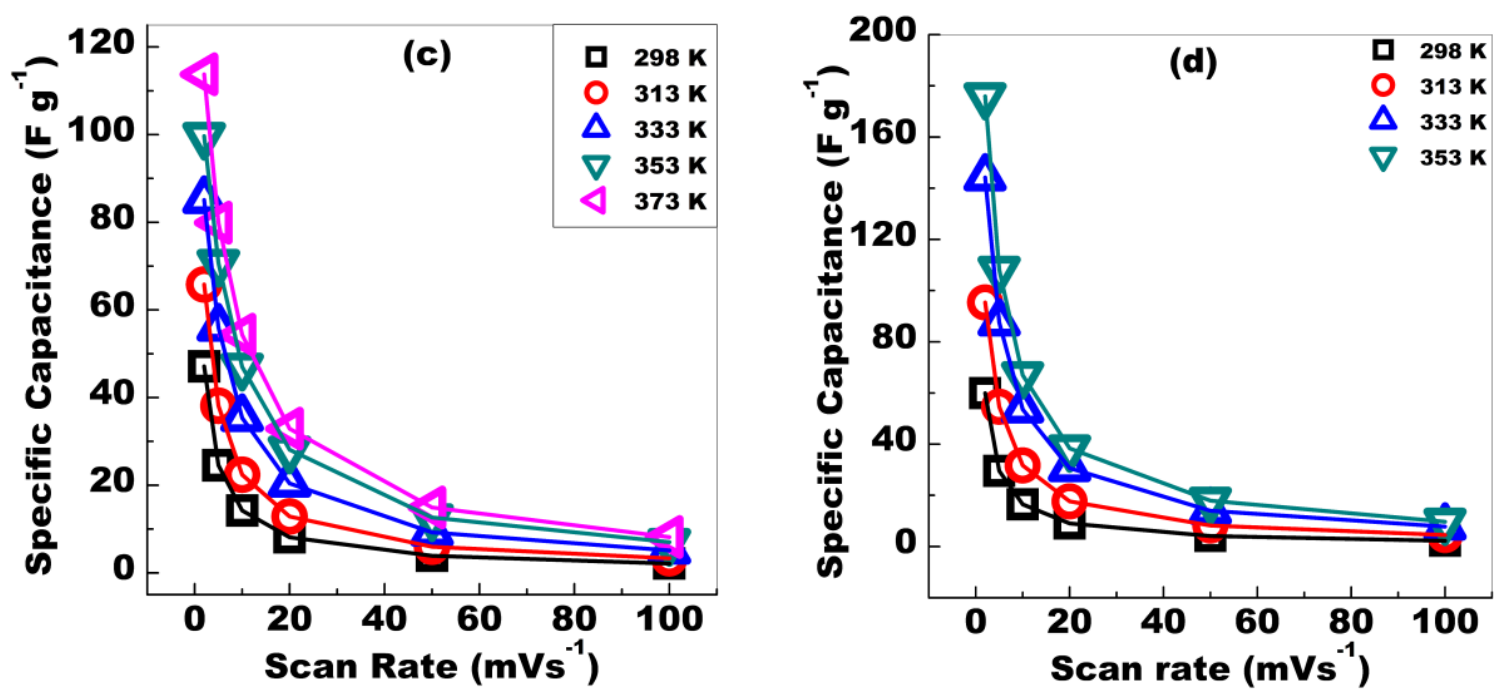

Figure 7. The specific capacitance values at different scan rates in the temperature range from 253 to $373 \mathrm{~K}$ for $\left[\mathrm{P}_{4444}\right][\mathrm{EHS}](\mathrm{a}),\left[\mathrm{C}_{6} \mathrm{C}_{1} \mathrm{IM}\right][\mathrm{EHS}](\mathrm{b})$ and $\left[\mathrm{P}_{66614}\right][\mathrm{EHS}]$ (c) where, $\mathrm{ECW}=$ $4 \mathrm{~V}$ and $\left[\mathrm{P}_{66614}\right][\mathrm{EHS}](\mathrm{d})$ with $5 \mathrm{~V}$ ECW.

The electrocapacitive performance of the SAILs also depends on its chemical structure as it might alter the interactions between the SAIL and the electrode surface. A recent study provided the evidence that the SAIL forms a stable EDL on the electrode surface. ${ }^{18}$ The rectangular shape of $\mathrm{CV}$ at higher temperatures at high scan rates also shows that the studied SAILs might indicate the formation of stable EDL layers and could be the reason for higher capacitance in particular with the smaller cations i.e. $\left[\mathrm{C}_{6} \mathrm{C}_{1} \mathrm{IM}\right]^{+}$and $\left[\mathrm{P}_{4444}\right]^{+}$. The specific capacitance values of supercapacitor cells with both MWCNTs and SAILs are much higher than those reported in the literature with RTILs and other electrolytes at the room temperature (ca. $298 \mathrm{~K})\left(15-80 \mathrm{~F} \mathrm{~g}^{-1}\right) .{ }^{42-45}$

To compare the effect of size and structure of cations, we performed similar electrochemical measurements by using $\left[\mathrm{P}_{4444}\right]^{+},\left[\mathrm{P}_{66614}\right]^{+}$, and $\left[\mathrm{C}_{6} \mathrm{C}_{1} \mathrm{IM}\right]^{+}$cation-based SAILs as electrolytes. The effect of these three different electrolytes can be compared from their CV curve shapes as shown in the ESI (Figures. S11, S12 and S13) and their specific capacitance values with respect to the temperature and scan rates are shown in Figure 7. A perfect rectangular shape is observed for the all the studied SAILs at lower scan rates, but the CV becomes distorted upon increasing the scan rate specifically for the $\left[\mathrm{P}_{4444}\right][\mathrm{EHS}]$ and $\left[\mathrm{P}_{66614}\right][\mathrm{EHS}]$ (Figures $\mathbf{S 1 1}$ and S13) at lower temperatures i.e., 298, 313 and $333 \mathrm{~K}$. Whereas for $\left[\mathrm{C}_{6} \mathrm{C}_{1} \mathrm{IM}\right][\mathrm{EHS}]$, the rectangular shape of the $\mathrm{CV}$ remain even up to high scan rates at $333 \mathrm{~K}$ and for other SAILs at 
the higher temperatures i.e., 353 and $373 \mathrm{~K}$ (Figure S11, S12, and S13). The CV curves and specific capacitance values indicate that the $\left[\mathrm{C}_{6} \mathrm{C}_{1} \mathrm{IM}\right][\mathrm{EHS}]$ can perform an appropriate electrolyte in the temperature range from 298 to $373 \mathrm{~K}$. It is in good accordance with the reported results and indicate a more stable EDL compared to the other studied SAILs with large cations i.e. $\left[\mathrm{P}_{66614}\right][\mathrm{EHS}]$ (this study) and $\left[\mathrm{N}_{8888}\right][\mathrm{EHS}] /$ aqueous electrolyte (previous study) even at high scan rates. ${ }^{18}$ As speculated for neat SAIL, upon increasing the temperature the mobility of ions increases as does their approach to the electrode and hence the ability to form a stable EDL. Perhaps this occurs because of the mobility of the ions in the $\left[\mathrm{C}_{6} \mathrm{C}_{1} \mathrm{IM}\right][\mathrm{EHS}]$ might be higher as compared to the $\left[\mathrm{P}_{4444}\right][\mathrm{EHS}]$ and $\left[\mathrm{P}_{66614}\right][\mathrm{EHS}]$ even at the lower temperatures i.e., 298 and $313 \mathrm{~K}$. Interaction between the constituent ions also plays an important role as it controls the mobility of ions. The imidazolium cation-based ILs know to have more mobile ions than the ammonium/phosphonium cation-based ILs. ${ }^{46}$ It is speculated that hydrogen bonding enhances the mobility in imidazolium-based ILs as compared to the quaternary ammonium/phosphonium-based ILs. Also, the imidazolium cation contains a conjugated cation structure, and the positive charge of imidazolium cation is well distributed on the ring atoms, which remarkebly wekeanes the coulombic interactions among ions. ${ }^{46-47}$ Therefore, the ions are readily available in the $\left[\mathrm{C}_{6} \mathrm{C}_{1} \mathrm{IM}\right][\mathrm{EHS}]$ as compared to the $\left[\mathrm{P}_{4444}\right][\mathrm{EHS}]$ and $\left[\mathrm{P}_{66614}\right][\mathrm{EHS}]$. Thus, the specific capacitance values for $\left[\mathrm{C}_{6} \mathrm{C}_{1} \mathrm{IM}\right][\mathrm{EHS}]$ are higher compared to these of the other two electrolytes and might be outcome of the smaller ion size and weak interionic interactions.

We further investigated the energy storage performance of the SAILs. The ECW for the aqueous electrolyte is only $1 \mathrm{~V}$ and other organic solvent-based electrolyte is around 2-3 V, which is relatively low when compared with the neat SAILs, i.e., 4-5V . Due to the higher ECW, the energy density for the capacitor is higher for neat SAILs at all temperatures compared to the other electrolytes. The order of the specific capacitance and energy densities from CV curves at $2 \mathrm{mV} \mathrm{s}^{-1}$ (see Figure $\mathbf{S 1 5}$ for CV curves at $2 \mathrm{mV} \mathrm{s}^{-1}$ at different temperatures for $\left[\mathrm{C}_{6} \mathrm{C}_{1} \mathrm{IM}\right][\mathrm{EHS}]$ and $\left.\left[\mathrm{P}_{4444}\right][\mathrm{EHS}]\right)$ in the whole temperature range as $\left[\mathrm{C}_{6} \mathrm{C}_{1} \mathrm{IM}\right][\mathrm{EHS}]>$ $\left[\mathrm{P}_{4444}\right][\mathrm{EHS}]>\left[\mathrm{N}_{8888}\right][\mathrm{EHS}]>\left[\mathrm{P}_{66614}\right][\mathrm{EHS}]$ as shown in the Figure 8(a) and (b), respectively. The data for $\left[\mathrm{N}_{8888}\right][\mathrm{EHS}]$ has been taken from the previous study. In contrast, the energy density and power density values at different scan rates for all the SAILs as electrolytes with a MWCNT-based supercapacitor are shown in Figure S16 and S17. [ $\left.\mathrm{P}_{4444}\right][$ EHS] can be used even at very low temperatures i.e., 253 and $273 \mathrm{~K}$ as an electrolyte but showed very low specific capacitance and energy density (Figure 8 (a) and (b)). 

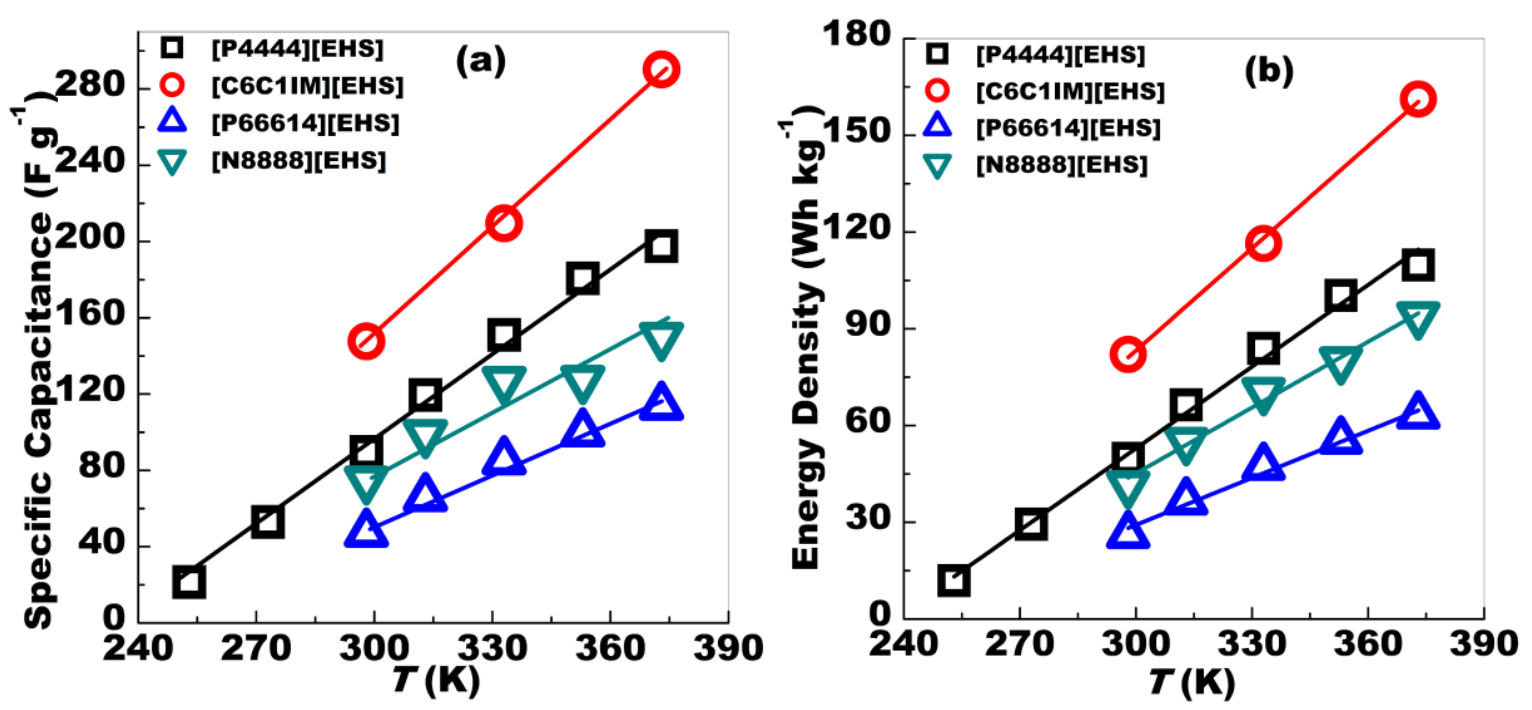

Figure 8. Specific capacitance (a), and the energy density (b) at $2 \mathrm{mVs}^{-1}$ for the different electrolytes studied.

At lower temperatures, the high viscosity of SAILs, $\left[\mathrm{P}_{66614}\right][\mathrm{EHS}]$ and $\left[\mathrm{P}_{4444}\right][\mathrm{EHS}]$ results in very low specific capacitance values. But, this SAIL can be used in wide range of temperature whereas, $\left[\mathrm{C}_{6} \mathrm{C}_{1} \mathrm{IM}\right][\mathrm{EHS}]$ can be used at and above the room temperature as have the melting point at $298 \mathrm{~K}$. However, at high temperatures all [ $\left.\mathrm{P}_{4444}\right][\mathrm{EHS}]$ and $\left[\mathrm{C}_{6} \mathrm{C}_{1} \mathrm{IM}\right][\mathrm{EHS}]$ become more fluid and outperforms the other two electrolytes ([ $\left.\mathrm{P}_{66614}\right][\mathrm{EHS}]$ and $\left.\left[\mathrm{N}_{8888}\right][\mathrm{EHS}]\right)$ in terms of both the specific capacitance and energy densities. Therefore, high energy density values make $\left[\mathrm{C}_{6} \mathrm{C}_{1} \mathrm{IM}\right][\mathrm{EHS}]$ and $\left[\mathrm{P}_{4444}\right][\mathrm{EHS}]$ suitable electrolyte for long range-temperature applications i.e., from 298 to $373 \mathrm{~K}^{48}$ Both low boiling points and instability at high temperature of many conventional aqueous and organic solvent electrolyte solutions limit their use at high temperatures as seen in the case of $6 \mathrm{M} \mathrm{KOH}$ aqueous electrolyte and the binary mixture of SAIL in our previous study as well. ${ }^{49-51}$ The higher specific capacitance, energy density and power density values were obtained from CV curves (Figure S18) for the enhanced ECW (5V) as compared to the ECW of $4 \mathrm{~V}$ for [P ${ }_{4444]}[\mathrm{EHS}]$ and tabulated in Table 1 at 298 and $373 \mathrm{~K}$ at 2 and $5 \mathrm{mV} \mathrm{s}^{-1}$. Similarly, the high energy density and power density values obtained and are shown in Figure S19 as a function of scan rate at different temperatures for $\left[\mathrm{P}_{66614}\right][\mathrm{EHS}]$ as electrolyte in the potential range of 5V $(-2.5$ to +2.5$)$. Therefore, $\left[\mathrm{P}_{4444}\right][\mathrm{EHS}]$ and $\left[\mathrm{P}_{66614}\right][\mathrm{EHS}]$ can be used in the high energy storage devices with higher specific capacitance, energy density and power density with wider ECW (5V) for the better performance. 
Table 1. Specific capacitance, energy density and power density for the $\left[\mathrm{P}_{4444}\right][\mathrm{EHS}]$ at 298 and $373 \mathrm{~K}$ with $\mathrm{ECW}=5 \mathrm{~V}$.

\begin{tabular}{|c|c|c|c|c|c|c|}
\hline $\begin{array}{c}\text { Temperature } \\
(\mathrm{K})\end{array}$ & \multicolumn{3}{|c|}{$2 \mathrm{mVs}^{-1}$} & \multicolumn{3}{c|}{$5 \mathrm{mVs}^{-1}$} \\
\hline & $\begin{array}{c}C_{\text {elec }} \\
\left(\mathrm{F} \mathrm{g}^{-1}\right)\end{array}$ & $\begin{array}{c}\text { Energy Density } \\
\left(\mathrm{Wh} \mathrm{kg}^{-1}\right)\end{array}$ & $\begin{array}{c}\text { Power density } \\
\left(\mathrm{kW} \mathrm{kg}^{-1}\right)\end{array}$ & $\begin{array}{c}C_{\text {elec }} \\
\left(\mathrm{F} \mathrm{g}^{-1}\right)\end{array}$ & $\begin{array}{c}\text { Energy Density } \\
\left(\mathrm{Wh} \mathrm{kg}^{-1}\right)\end{array}$ & $\begin{array}{c}\text { Power density } \\
\left(\mathrm{kW} \mathrm{kg}^{-1}\right)\end{array}$ \\
\hline 298 & 132 & 74 & 106 & 87 & 48 & 174 \\
\hline 373 & 285 & 158 & 228 & 229 & 127 & 458 \\
\hline
\end{tabular}

\section{Electrochemical Impedance Spectroscopy (EIS):}

EIS analysis provides fundamental understanding of electrode/electrolyte interface behavior, ion diffusion and bulk properties of the electrolytes, etc. and has been used extensively to characterize the performance of electrical energy storage devices. ${ }^{52-54}$ The EIS data were analyzed to determine the charge-transfer $\left(\mathrm{R}_{\mathrm{ct}}\right)$ and solution resistance $\left(\mathrm{R}_{\mathrm{s}}\right)$ in different recorded frequency regions. Figure 9 shows the impedance spectra (Nyquist plots) for all the studied systems at different temperatures. The Nyquist plots show a semicircle in the high frequency region, the Warburg line in the intermediate frequency region and almost a vertical line in the low frequency region because of the charge storage mechanism. ${ }^{55}$ The Nyquist plots were fitted using modified Randal's circuit (Figure S20) with RelaxIS 3 software. The circuit comprises $R_{s}$ (solution resistance), $R_{c t}$ (charge transfer resistance), CPE (constant phase element), $W$ (Warburg component), and $C_{d l}$ (double layer capacitance).

Figures 9(a), 9(b) and 9(c) (inset) show the Warburg diffusion region with slope $\sim 45^{\circ}$ from the horizontal axis for the neat SAILs. The steeper slope signifies higher diffusivity of ions entering the pores, which is prominent for the $\left[\mathrm{C}_{6} \mathrm{C}_{1} \mathrm{IM}\right][\mathrm{EHS}]$ compared to the $\left[\mathrm{P}_{4444}\right][\mathrm{EHS}]$ and $\left[\mathrm{P}_{66614}\right][\mathrm{EHS}]$. The steep rising trend of the imaginary part ( $-Z$ ”) with respect to the real part $\left(Z^{\prime}\right)$ of the impedance is observed in Nyquist plot for the SAILs particularly at high temperatures $(333,353$ and $373 \mathrm{~K})$ for the neat SAILs in the lower frequency range shows greater capacitive behavior of the capacitor. The intersection between the vertical line and real $Z^{\prime}$ axis corresponds to the equivalent series resistance (ESR) and was estimated by an extrapolation method via Origin Pro 8.0 software. Values are given in Table 3 (Figure S21). The ESR shifted to lower values upon increasing the temperature, which confirms the increasing ion conductance and mobility at higher temperatures. 

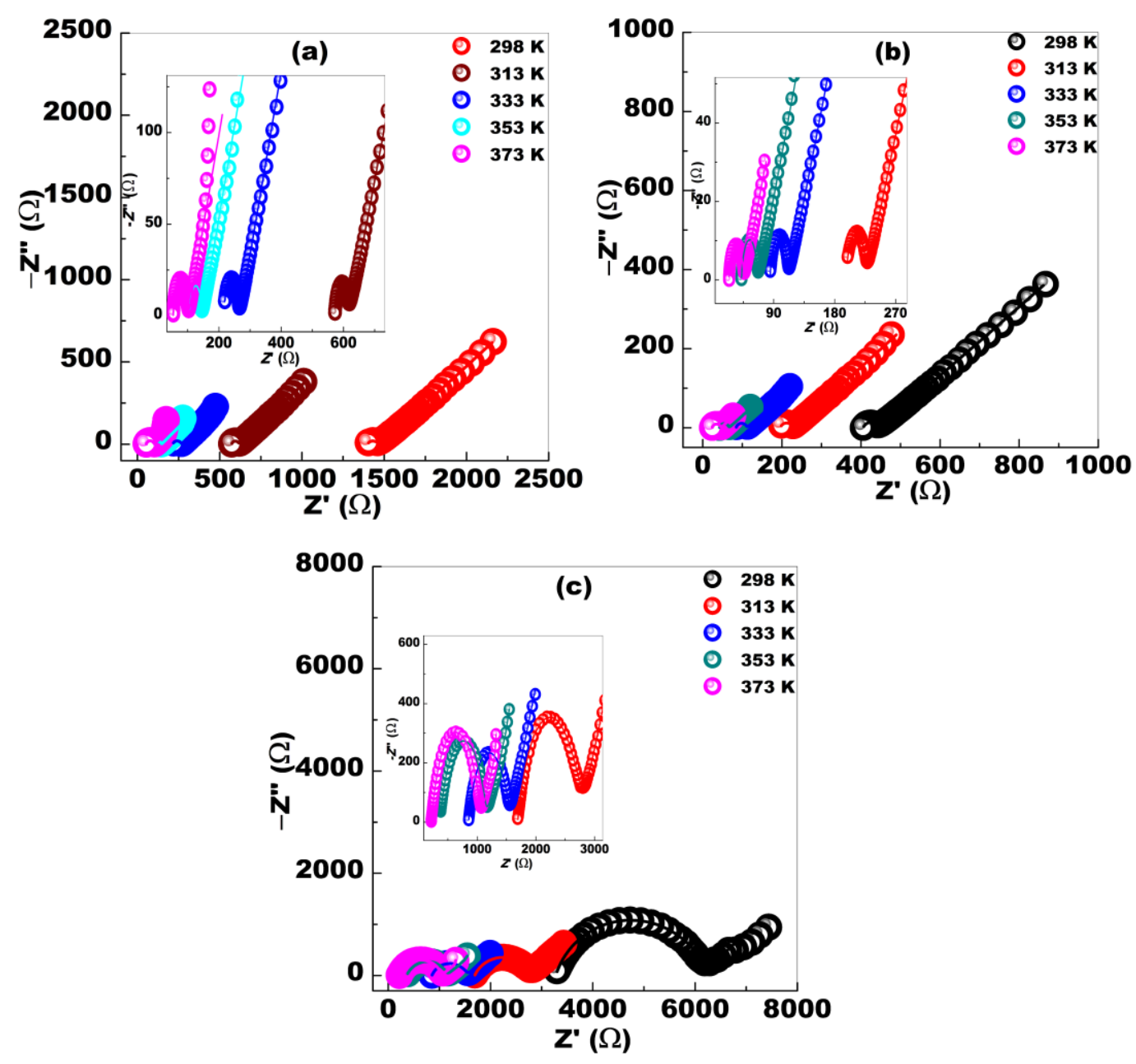

Figure 9. Nyquist plots at different temperatures for an MWCNT-based electrode with neat $\left[\mathrm{P}_{4444}\right][\mathrm{EHS}](\mathbf{a})\left[\mathrm{C}_{6} \mathrm{C}_{1} \mathrm{IM}\right][\mathrm{EHS}](\mathbf{b})$ and $\left[\mathrm{P}_{66614}\right][\mathrm{EHS}](\mathbf{c})$ as electrolytes.

The Nyquist plot shows small semicircles in the high-frequency region for all SAILs in order of $\left[\mathrm{C}_{6} \mathrm{C}_{1} \mathrm{IM}\right][\mathrm{EHS}]<\left[\mathrm{P}_{4444}\right][\mathrm{EHS}]<\left[\mathrm{P}_{66614}\right][\mathrm{EHS}]$, confirms faster charge transfer and a high capacitance for $\left[\mathrm{C}_{6} \mathrm{C}_{1} \mathrm{IM}\right][\mathrm{EHS}]$ in the whole temperature range. The $R_{s}$ and $R_{c t}$ values are given in Table 2 for an MWCNT-based electrode and different electrolytes. Also, with an increase in temperature, the $R_{s}$ (from 1856 to $54 \Omega$, for temperatures from 253 to $373 \mathrm{~K}$ ) and $R_{c t}$ (from 14510 to $48 \Omega$, for temperatures from 253 to $373 \mathrm{~K}$ ) for neat $\left[\mathrm{P}_{4444}\right][\mathrm{EHS}$ ] significantly decrease. These values for both $R_{s}$ and $R_{c t}$ are even much lower than those of the [ $\left.\mathrm{P}_{66614}\right]$ [EHS].

Table 2. The solution resistance $\left(R_{s}\right)$ and the charge transfer resistance $\left(R_{c t}\right)$ values obtained from the Nyquist plots.

\begin{tabular}{|c|c|c|c|c|c|c|}
\hline \multirow{2}{*}{$\begin{array}{c}\text { Temperature } \\
(\mathbf{K})\end{array}$} & \multicolumn{2}{|c|}{$\left[\mathbf{C}_{6} \mathbf{C}_{\mathbf{1}} \mathbf{I M}\right][\mathbf{E H S}]$} & \multicolumn{2}{|c|}{$\left[\mathbf{P}_{4444}\right][\mathbf{E H S}]$} & \multicolumn{2}{|c|}{$\left[\mathbf{P}_{66614]}[\mathbf{E H S}]\right.$} \\
\cline { 2 - 7 } & $\mathrm{R}_{\mathrm{ct}}(\Omega)$ & $\operatorname{Rct}(\Omega)$ & $\mathrm{R}_{\mathrm{s}}(\Omega)$ & $\mathrm{R}_{\mathrm{ct}}(\Omega)$ & $\mathrm{R}_{\mathrm{s}}(\Omega)$ & $\mathrm{R}_{\mathrm{ct}}(\Omega)$ \\
\hline 253 & & & $1856 \pm 130$ & $14510 \pm 136$ & & \\
\hline
\end{tabular}




\begin{tabular}{|c|c|c|c|c|c|c|}
\hline 273 & & & $1607 \pm 90$ & $3631 \pm 15$ & & \\
\hline 298 & $405 \pm 1$ & $32 \pm 0.90$ & $1398 \pm 1$ & $136 \pm 3$ & $3277 \pm 10$ & $2890 \pm 18$ \\
\hline 313 & $196 \pm 1$ & $28 \pm 0.68$ & $570 \pm 1$ & $37 \pm 1$ & $1691 \pm 1$ & $1080 \pm 2$ \\
\hline 333 & $84 \pm 0.15$ & $26 \pm 0.40$ & $215 \pm 1$ & $52 \pm 1$ & $853 \pm 1$ & $691 \pm 1$ \\
\hline 353 & $42 \pm 0.08$ & $23 \pm 0.20$ & $105 \pm 1$ & $42 \pm 1$ & $686 \pm 1$ & $878 \pm 2$ \\
\hline 373 & $24 \pm 0.19$ & $21 \pm 0.32$ & $54 \pm 1$ & $48 \pm 1$ & $217 \pm 1$ & $846 \pm 2$ \\
\hline
\end{tabular}

Table 3. The equivalent series resistance (ESR) values obtained from the Nyquist plots by extrapolation.

\begin{tabular}{|c|c|c|c|}
\hline $\begin{array}{c}\text { Temperature } \\
(\mathbf{K})\end{array}$ & {$\left[\mathbf{C}_{6} \mathbf{C}_{\mathbf{1}} \mathbf{I M}\right][\mathbf{E H S}]$} & {$\left[\mathbf{P}_{4444}\right][\mathbf{E H S}]$} & {$\left[\mathbf{P}_{66614}\right][\mathbf{E H S}]$} \\
\hline 333 & $221 \pm 2$ & $468 \pm 5$ & $1994 \pm 20$ \\
\hline 353 & $117 \pm 1$ & $264 \pm 3$ & $1517 \pm 15$ \\
\hline 373 & $72 \pm 1$ & $163 \pm 1$ & $1287 \pm 13$ \\
\hline
\end{tabular}

\section{Galvanostatic Charge Discharge (GCD)}

We further performed GCD experiments to check the performance of the capacitor. Figure 10 shows the comparative GCD curves for the MWCNT-based supercapacitor with the neat SAILs at different temperatures. We observed that all curves have similar isosceles triangular shapes that represent a typical pattern of satisfactory capacitor behavior for the studied supercapacitors. The steep $I R_{\text {drop }}$ was observed for the pure SAILs at lower temperatures, i.e., 298 and $313 \mathrm{~K}_{\text {at }} 0.14 \mathrm{~A} \mathrm{~g}^{-1}$. Upon increasing the current density, the $I R_{\text {drop }}$ further increased at these temperatures. This might be a result of the high viscosity and small pore size of the electrode material compared to the ions of the electrolyte. The $I R_{\text {drop }}$ corresponds to the ESR of the supercapacitor cell, which is associated with the diffusion mobility of the electrolyte ions travelling through the pores of the electrode. However, it can also be observed that the areas under the curve and the discharge period are different corresponding to each system, being at a maximum at $373 \mathrm{~K}$ for the neat SAILs and exhibiting a better capacitive performance at 373 K compared to lower temperatures. The GCD curves at different current densities are provided in the ESI for [ $\left.\mathrm{P}_{4444}\right][\mathrm{EHS}]$ at 0.07 and $0.11 \mathrm{~A} \mathrm{~g}^{-1}$ (Figure S22) and for $\left[\mathrm{C}_{6} \mathrm{C}_{1} \mathrm{IM}\right][\mathrm{EHS}]$ at 0.11 $\mathrm{A} \mathrm{g}^{-1}$ (Figure S23). Whereas, for [ $\left.\mathrm{P}_{66614}\right][\mathrm{EHS}] \mathrm{GCD}$ curves obtained only at very low current density i.e., $0.014 \mathrm{~A} \mathrm{~g} \mathrm{~g}^{-1}$ (Figure S24) due to high viscosity. The values of the specific capacitance of the supercapacitor cell were calculated from the GCD curves by using the following equation: 


$$
C_{\text {elec }}=4 \frac{\mathrm{I} \Delta \mathrm{t}}{\mathrm{m} \Delta \mathrm{V}}
$$

where, $\Delta t=$ discharge time, $\Delta V=$ voltage difference, $I=$ current, and $m=$ mass of the electrode.

Table 4 and 5 shows the values of $C_{\text {elec }}\left(\mathrm{F} \mathrm{g}^{-1}\right)$ and energy densities, $E\left(\mathrm{Wh} \mathrm{kg}^{-1}\right)$ calculated from the GCD curves and $\mathrm{CV}$ curves at $10 \mathrm{mVs}^{-1}$ for $\left[\mathrm{C}_{6} \mathrm{C}_{1} \mathrm{IM}\right][\mathrm{EHS}]$ and [P $\left.\mathrm{P}_{4444}\right][\mathrm{EHS}]$, respectively. The $C_{\text {elec }}$ values obtained from GCD curves at lower current densities are in a good correlation with those obtained from the CV curves.
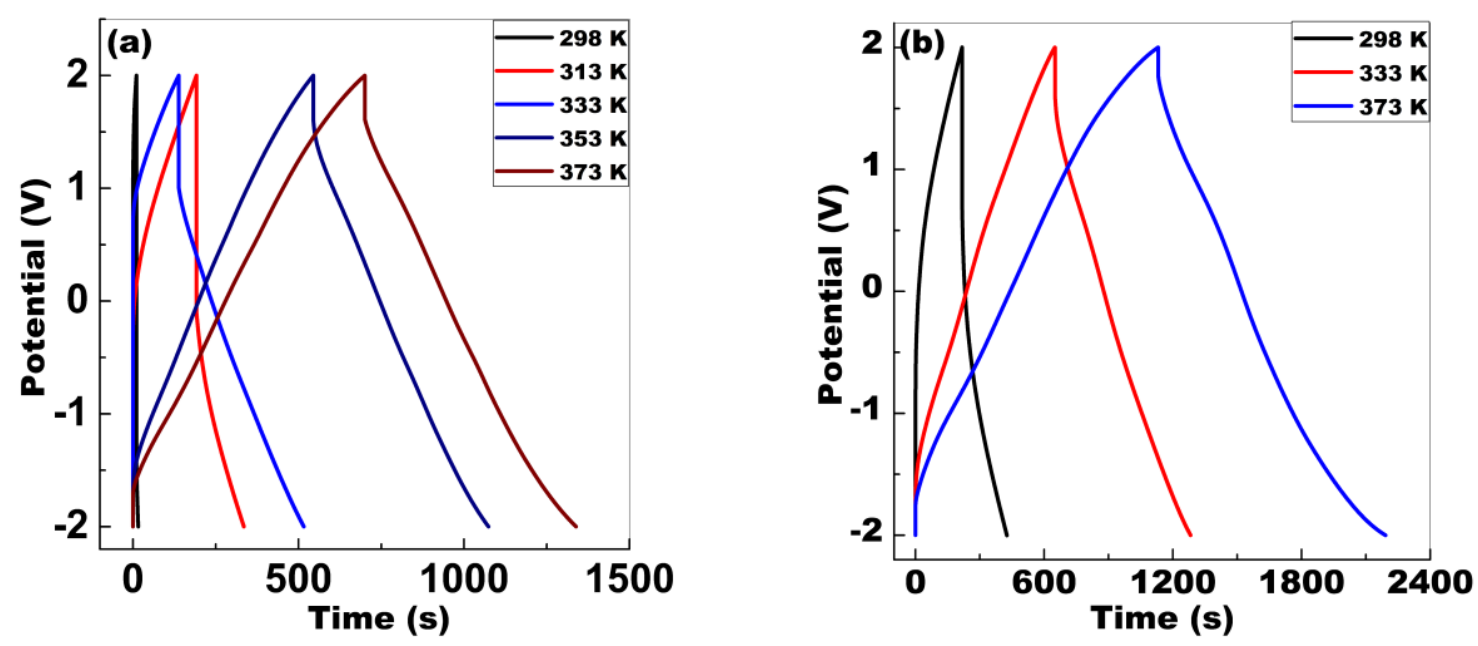

Figure 10. Galvanostatic charge discharge curves for an MWCNT-based electrode with the neat $\left[\mathrm{P}_{4444}\right][\mathrm{EHS}](\mathrm{a})$, and $\left[\mathrm{C}_{6} \mathrm{C}_{1} \mathrm{IM}\right][\mathrm{EHS}]$ (b) as electrolyte, at $0.14 \mathrm{~A} \mathrm{~g}^{-1}$ current density at different temperatures.

Table 4. The specific capacitance of the supercapacitor cell $\left(C_{\text {elec }}\right)$, and the energy density $(E)$ for an MWCNT-based electrode with neat $\left[\mathrm{C}_{6} \mathrm{C}_{1} \mathrm{IM}\right][\mathrm{EHS}]$ as an electrolyte.

\begin{tabular}{|c|c|c|c|c|c|c|}
\hline \multirow{2}{*}{$\begin{array}{c}\text { Temperature } \\
(\mathbf{K})\end{array}$} & \multicolumn{2}{|c|}{ CV at 10 $\mathbf{~ V s}^{-1}$} & \multicolumn{2}{c|}{ GCD at 0.11 $\mathbf{~ g ~ g}^{-1}$} & \multicolumn{2}{c|}{ GCD at 0.14 $\mathbf{A ~ g}^{-1}$} \\
\cline { 2 - 7 } & $C_{\text {elec }}\left(\mathrm{F} \mathrm{g}^{-1}\right)$ & $E\left(\mathrm{Wh} \mathrm{kg}^{-1}\right)$ & $C_{\text {elec }}\left(\mathrm{F} \mathrm{g}^{-1}\right)$ & $E\left(\mathrm{Wh} \mathrm{kg}^{-1}\right)$ & $C_{\text {elec }}\left(\mathrm{F} \mathrm{g}^{-1}\right)$ & $E\left(\mathrm{Wh} \mathrm{kg}^{-1}\right)$ \\
\hline 298 & 71 & 40 & 66 & 33 & 44 & 22 \\
\hline 333 & 158 & 88 & 113 & 106 & 100 & 91 \\
\hline 373 & 224 & 125 & 180 & 180 & 160 & 159 \\
\hline
\end{tabular}

Table 5. The specific capacitance of the supercapacitor cell $\left(C_{\text {elec }}\right)$, and energy density $(E)$ for an MWCNT-based electrode with neat $\left[\mathrm{P}_{4444}\right][\mathrm{EHS}]$ as an electrolyte.

\begin{tabular}{|c|c|c|c|c|c|c|c|c|}
\hline \multirow{2}{*}{$\begin{array}{c}\text { Temperature } \\
\text { (K) }\end{array}$} & \multicolumn{2}{|c|}{$\mathrm{CV}$ at $10 \mathrm{mVs}^{-1}$} & \multicolumn{2}{|c|}{ GCD at $0.07 \mathrm{Ag}^{-1}$} & \multicolumn{2}{|c|}{ GCD at $0.11 \mathrm{Ag}^{-1}$} & \multicolumn{2}{|c|}{ GCD at $0.14 \mathrm{Ag}^{-1}$} \\
\hline & $\begin{array}{l}C_{\text {elec }} \\
\left(\mathrm{F} \mathrm{g}^{-1}\right)\end{array}$ & $\begin{array}{c}E \\
\left(\mathrm{Wh} \mathrm{kg}^{-1}\right)\end{array}$ & $\begin{array}{l}C_{\text {elec }} \\
\left(\mathrm{F} \mathrm{g}^{-1}\right)\end{array}$ & $\begin{array}{c}E \\
\left(\mathrm{Wh} \mathrm{kg}^{-1}\right)\end{array}$ & $\begin{array}{l}C_{\text {elec }} \\
\left(\mathrm{F} \mathrm{g}^{-1}\right)\end{array}$ & $\begin{array}{c}E \\
\left(\mathrm{Wh} \mathrm{kg}^{-1}\right)\end{array}$ & $\begin{array}{c}C_{\text {elec }} \\
\left(\mathrm{F} \mathrm{g} \mathrm{g}^{-1}\right)\end{array}$ & $\begin{array}{c}E \\
\left(\mathrm{Wh} \mathrm{kg}^{-1}\right)\end{array}$ \\
\hline 298 & 34 & 19 & 25 & 9 & 10 & 1 & 5 & 1 \\
\hline
\end{tabular}




\begin{tabular}{|l|c|c|c|c|c|c|c|c|}
\hline 313 & 65 & 36 & 55 & 40 & 47 & 22 & 43 & 11 \\
\hline 333 & 106 & 59 & 77 & 71 & 74 & 55 & 72 & 45 \\
\hline 353 & 137 & 76 & 92 & 92 & 93 & 88 & 84 & 76 \\
\hline 373 & 158 & 88 & 117 & 118 & 112 & 112 & 101 & 92 \\
\hline
\end{tabular}

At the end, $500 \mathrm{CV}$ cycles with a scan rate of $50 \mathrm{mVs}^{-1}$ at $298 \mathrm{~K}$ and $333 \mathrm{~K}$ were recorded for an MWCNT-based electrode with $\left[\mathrm{C}_{6} \mathrm{C}_{1} \mathrm{IM}\right][\mathrm{EHS}]$, and $\left[\mathrm{P}_{4444}\right][\mathrm{EHS}]$ as electrolyte, respectively. While for [ $\left.\mathrm{P}_{66614}\right][\mathrm{EHS}] 100$ cycles were recorded at $25 \mathrm{mVs}^{-1}$ at $298 \mathrm{~K}$ and 50 cycles were recorded at $25 \mathrm{mVs}^{-1}$ at $373 \mathrm{~K}$. From Figure 11, it is evident that the [P4444][EHS] exhibited a good capacitance retention (98\%), [ $\left.\mathrm{C}_{6} \mathrm{C}_{1} \mathrm{IM}\right][\mathrm{EHS}]$ shows that the capacitance increases with the number of cycles whereas, $\left[\mathrm{P}_{66614}\right][\mathrm{EHS}]$ show the $99 \%$ retention in capacitance after completing all the experiments. The overlapping curves were seen for the CVs ( $1^{\text {st }}$ and last CV cycle) during the cyclic test as shown in Figure $\mathbf{S 2 5}$ and $\mathbf{S 2 6}$. The EIS measurements were also performed before and after cyclic test and showed a significant overlap of EIS data as shown in Figure S27. After completion of all the experiments from 298 to $373 \mathrm{~K}$, and cyclic test the CV shows a good overlapping (Figure S28) for the studied SAILs, which indicates a good thermal and electrochemical stability of all SAILs. 

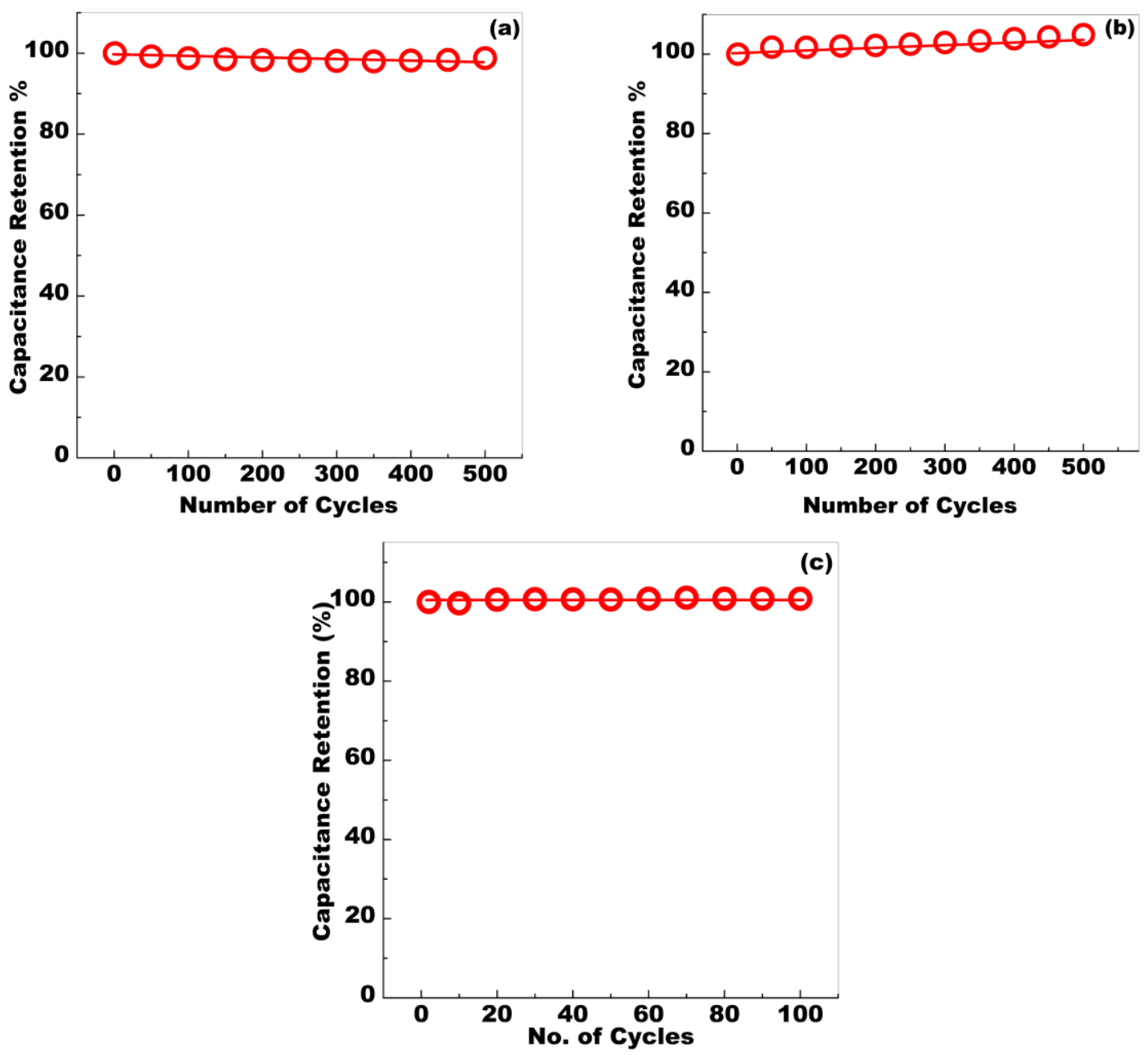

Figure 11. The capacitance retention of $\mathrm{CV}$ cycles at $50 \mathrm{mV} \mathrm{s}^{-1}$ at $333 \mathrm{~K}$ after completing all the experiments up to $373 \mathrm{~K}$ for the MWCNT-based electrode and the neat $\left[\mathrm{P}_{4444}\right][\mathrm{EHS}]$ as an electrolyte (a), at $50 \mathrm{mV} \mathrm{s}^{-1}$ at $298 \mathrm{~K}$ for the MWCNT-based electrode and $\left[\mathrm{C}_{6} \mathrm{C}_{1} \mathrm{IM}\right][\mathrm{EHS}]$ as an electrolyte (b) and at $25 \mathrm{mV} \mathrm{s}^{-1}$ at $298 \mathrm{~K}$ for the MWCNT-based electrode and [P66614][EHS] as an electrolyte (c).

\section{Ragone plot}

We further quantified the power density and energy density of the supercapacitors as it is a crucial parameter in choosing an appropriate electrode-electrolyte. The power density, $P$, and energy density, $E$, calculated using Eqs. (2) and (3) are plotted against each other and generally referred as the Ragone plot. The Ragone plot (Figure 12) shows that the $\left[\mathrm{C}_{6} \mathrm{C}_{1} \mathrm{IM}\right][\mathrm{EHS}]$ outperforms other electrolytes in this study in the temperature range from 298 to $373 \mathrm{~K}$ The comparison between the Ragone plot for the all SAILs at different temperatures infers that $\left[\mathrm{C}_{6} \mathrm{C}_{1} \mathrm{IM}\right][\mathrm{EHS}]$ have better energy and power densities compared to the other electrolytes. The energy density of $82 \mathrm{Wh} \mathrm{kg}^{-1}$ with a power density of $148 \mathrm{~kW} \mathrm{~kg}^{-1}$ at $2 \mathrm{mVs}^{-1}$ is obtained at 
$298 \mathrm{~K}$ for the MWCNT-based electrode and $\left[\mathrm{C}_{6} \mathrm{C}_{1} \mathrm{IM}\right][\mathrm{EHS}]$ as an electrolyte. These values can be further improved upon increasing the temperature, i.e., up to the energy density of 161 Wh kg-1 and the power density of $290 \mathrm{~kW} \mathrm{~kg}^{-1}$ at $2 \mathrm{mVs}^{-1}$ at $373 \mathrm{~K}$. The energy density and power density increases for $\left[\mathrm{P}_{4444}\right][\mathrm{EHS}]$ and $\left[\mathrm{P}_{66614}\right][\mathrm{EHS}]$ from 50 to $100 \mathrm{Wh} \mathrm{kg}^{-1}$ and 90 to $110 \mathrm{~kW} \mathrm{~kg}^{-1}$ and 26 to $63 \mathrm{Wh} \mathrm{kg}^{-1}, 47$ to $114 \mathrm{~kW} \mathrm{~kg}^{-1}$, respectively. The electrochemical performance of the studied supercapacitor is better than those reported for halogenated ILs as electrolytes. $^{56-59}$
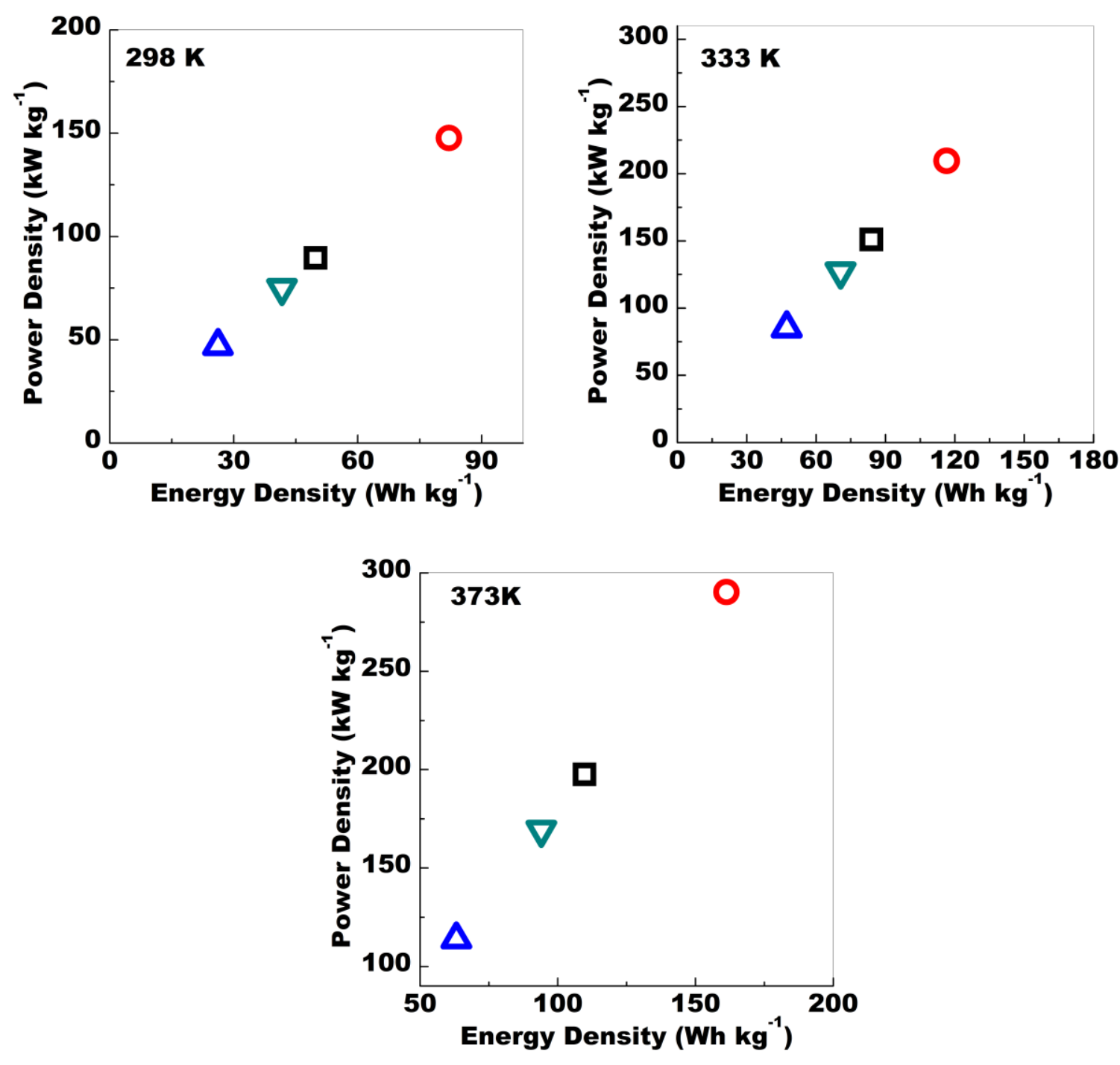

Figure 12. Ragone plots of a supercapacitor with an MWCNT-based electrode and $[\mathrm{P} 4444][\mathrm{EHS}](\square),[\mathrm{C6C1IM}][\mathrm{EHS}](\mathrm{O}),[\mathrm{P} 66614][\mathrm{EHS}](\triangle)$, and [N8888][EHS] $(\nabla)$ as electrolytes at $2 \mathrm{mVs}^{-1}$ at different temperatures. 
After a thorough and comparative analysis, we conclude that SAILs, such as $\left[\mathrm{C}_{6} \mathrm{C}_{1} \mathrm{IM}\right][\mathrm{EHS}]$, [P 4444$][\mathrm{EHS}],\left[\mathrm{P}_{66614}\right][\mathrm{EHS}]$ and [ $\left.\mathrm{N}_{8888}\right][\mathrm{EHS}]$ (from previous study) can be considered a valueadded electrolyte in supercapacitor devices over a wide operating temperature range with good thermal and chemical stability and high specific capacitance, energy density, and power density.

\section{Conclusions}

We are reporting for the first time a combination of different cations $\left(\left[\mathrm{P}_{4444}\right]^{+},\left[\mathrm{C}_{6} \mathrm{C}_{1} \mathrm{IM}\right]^{+}\right.$, $\left(\left[\mathrm{P}_{66614}\right]^{+}\right)$and anion $\left([\mathrm{EHS}]^{-}\right)$representing SAILs that exist as a liquid at room temperature, whereas other halogenated ILs containing tetra alkylammonium/tetrabutylphosphonium as cation with halogen-containing anions are solid in nature. However, the specific capacitance values for the supercapacitor cell $\left(C_{\text {elec }}\right)$ are in a good association with the reported values of $C_{\text {elec }}$ for other SAILs. This study reveals that the SAILs, can be used as an improved and safer electrolyte in the wide range of temperature in supercapacitor cells. The studied SAILs are economical and environmentally benign, therefore it can be used at large scale without polluting the environment. The degradation temperature is higher than the $550 \mathrm{~K}$ and can be used at even higher temperatures than studied here, i.e., $373 \mathrm{~K}$, which is the temperature limit of Autolab potentiostat. The ECW data showed a better performance of the ionic liquid (ECW $\approx 4-5 \mathrm{~V}$ ) than aqueous and other organic solvent-based electrolytes. At room temperature (298

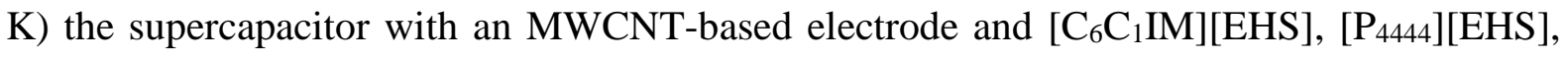
and $\left[\mathrm{P}_{66614}\right][\mathrm{EHS}]$ as an electrolyte showed a specific capacitance of the supercapacitor cell of 148,90 , and $47 \mathrm{~F} \mathrm{~g}^{-1}$ (at scan rate of $2 \mathrm{mV} \mathrm{s}^{-1}$ ) with an energy density of 82, 50, and $26 \mathrm{Wh} \mathrm{kg}^{-}$

${ }^{1}$ (at $2 \mathrm{mV} \mathrm{s}^{-1}$ ), respectively. The significant effect of temperature can be seen by the three to four-fold increase in the specific capacitance of the cell and the energy density values, i.e., 290, 198, and $114 \mathrm{~F} \mathrm{~g}^{-1}$ (at $2 \mathrm{mV} \mathrm{s}^{-1}$ ) and 161, 110, and $63 \mathrm{Wh} \mathrm{kg}^{-1}$ (at $2 \mathrm{mV} \mathrm{s}^{-1}$ ), respectively, at $373 \mathrm{~K}$. Therefore these SAILs can be consider as suitable electrolyte for high-temperature applications such as powering energy devices in the oil and gas industries and in military and space applications. Overall, the supercapacitor with the $\left[\mathrm{C}_{6} \mathrm{C}_{1} \mathrm{IM}\right][\mathrm{EHS}] \mathrm{SAIL}$ as an electrolyte outperformed other electrolytes in this study at variable temperatures and in a wide potential range along with a good thermal and electrochemical stability. Due to the high thermal and electrochemical stability of the newly synthesized SAILs, [ $\left.\mathrm{C}_{6} \mathrm{C}_{1} \mathrm{IM}\right][\mathrm{EHS}]$, and [ $\left.\mathrm{P}_{4444}\right][\mathrm{EHS}]$, can be considered as electrolytes in high-temperature applications. This paves the way for building "designer" SAILs, since there are a large number of possible anion-cation combinations that can be exploited to generate less viscous and more conductive ILs. 


\section{Acknowledgements}

The Kempe Foundation in memory of J. C. and Seth M. Kempe is gratefully acknowledged for the financial support in the form of a stipend for P.J. (Grant No. JCK-1810), and the project numbers JCK-1306 and JCK-1433 and the laboratory fund at LTU for providing grants, from which a Bruker Aeon/Avance III NMR spectrometer at LTU has been purchased.

\section{References:}

1. Lei, Z. G.; Chen, B. H.; Koo, Y. M.; MacFarlane, D. R., Introduction: Ionic liquids. Chem. Rev. 2017, 117 (10), 6633-6635.

2. Galinski, M.; Lewandowski, A.; Stepniak, I., Ionic liquids as electrolytes. Electrochim. Acta 2006, 51 (26), 5567-5580.

3. Earle, M. J.; Seddon, K. R., Ionic liquids: Green solvents for the future. Acs. Sym. Ser. 2002, $819,10-25$.

4. Armand, M.; Endres, F.; MacFarlane, D. R.; Ohno, H.; Scrosati, B., Ionic-liquid materials for the electrochemical challenges of the future. Nat. Mater. 2009, 8 (8), 621-629.

5. MacFarlane, D. R.; Forsyth, M.; Howlett, P. C.; Kar, M.; Passerini, S.; Pringle, J. M.; Ohno, H.; Watanabe, M.; Yan, F.; Zheng, W. J.; Zhang, S. G.; Zhang, J., Ionic liquids and their solidstate analogues as materials for energy generation and storage. Nat. Rev. Mater. 2016, 1 (2).

6. Griffin, P. J.; Holt, A. P.; Tsunashima, K.; Sangoro, J. R.; Kremer, F.; Sokolov, A. P., Ion transport and structural dynamics in homologous ammonium and phosphonium-based room temperature ionic liquids. J. Chem. Phys. 2015, 142 (8), 84501-84507.

7. Sun, J. Z.; MacFarlane, D. R.; Forsyth, M., Synthesis and properties of ambient temperature molten salts based on the quaternary ammonium ion. Ionics 1997, 3 (5-6), 356-362.

8. Sun, J.; Forsyth, M.; MacFarlane, D. R., Room-temperature molten salts based on the quaternary ammonium ion. J. Phys. Chem. B 1998, 102 (44), 8858-8864.

9. Tsunashima, K.; Sugiya, M., Physical and electrochemical properties of low-viscosity phosphonium ionic liquids as potential electrolytes. Electrochem. Commun. 2007, 9 (9), 23532358.

10. Shimizu, K.; Padua, A. A. H.; Lopes, J. N. C., Nanostructure of trialkylmethylammonium bistriflamide ionic liquids studied by molecular dynamics. J. Phys. Chem. B 2010, 114 (47), 15635-15641. 
11. Griffin, P. J.; Holt, A. P.; Wang, Y. Y.; Novikov, V. N.; Sangoro, J. R.; Kremer, F.; Sokolov, A. P., Interplay between hydrophobic aggregation and charge transport in the ionic liquid methyltrioctylammonium bis(trifluoromethylsulfonyl)imide. J. Phys. Chem. B 2014, 118 (3), 783-790.

12. Hilder, M.; Girard, G. M. A.; Whitbread, K.; Zavorine, S.; Moser, M.; Nucciarone, D.; Forsyth, M.; MacFarlane, D. R.; Howlett, P. C., Physicochemical characterization of a new family of small alkyl phosphonium imide ionic liquids. Electrochim. Acta 2016, 202, 100-109. 13. Blundell, R. K.; Licence, P., Quaternary ammonium and phosphonium based ionic liquids: a comparison of common anions. Phys. Chem. Chem. Phys. 2014, 16 (29), 15278-15288.

14. Yoshii, K.; Yamaji, K.; Tsuda, T.; Tsunashima, K.; Yoshida, H.; Ozaki, M.; Kuwabata, S., physicochemical properties of tri-n-butylalkylphosphonium cation-based room-temperature ionic liquids. J. Phys. Chem. B 2013, 117 (48), 15051-15059.

15. Galiński, M.; Lewandowski, A.; Stępniak, I., Ionic liquids as electrolytes. Electrochim. Acta 2006, 51 (26), 5567-5580.

16. Pan, S. S.; Yao, M.; Zhang, J. H.; Li, B. S.; Xing, C. X.; Song, X. L.; Su, P. P.; Zhang, H. T., Recognition of ionic liquids as high-voltage electrolytes for supercapacitors. Front. Chem. 2020, 8 .

17. Bandhauer, T. M.; Garimella, S.; Fuller, T. F., A critical review of thermal issues in lithiumion batteries. J. Electrochem. Society 2011, 158 (3), R1-R25.

18. Mao, X. W.; Brown, P.; Cervinka, C.; Hazell, G.; Li, H.; Ren, Y. Y.; Chen, D.; Atkin, R.; Eastoe, J.; Grillo, I.; Padua, A. A. H.; Gomes, M. F. C.; Hatton, T. A., Self-assembled nanostructures in ionic liquids facilitate charge storage at electrified interfaces. Nat Mater 2019, 18 (12), 1350-1357.

19. Fedorov, M. V.; Kornyshev, A. A., Ionic liquids at electrified interfaces. Chem. Rev. 2014, 114 (5), 2978-3036.

20. Salanne, M.; Rotenberg, B.; Naoi, K.; Kaneko, K.; Taberna, P. L.; Grey, C. P.; Dunn, B.; Simon, P., Efficient storage mechanisms for building better supercapacitors. Nat. Energy 2016, 1 .

21. Bazant, M. Z.; Storey, B. D.; Kornyshev, A. A., Double layer in ionic liquids: overscreening versus crowding Phys. Rev. Lett. 2011, 106 (14), $046102-046105$ (Erratum: Phys. Rev. Lett. 2012, 109, 149903).

22. Gebbie, M. A.; Dobbs, H. A.; Valtiner, M.; Israelachvili, J. N., Long-range electrostatic screening in ionic liquids. P. Natl. Acad. Sci. USA 2015, 112 (24), 7432-7437. 
23. Zhou, H.; Rouha, M.; Feng, G.; Lee, S. S.; Docherty, H.; Fenter, P.; Cummings, P. T.; Fulvio, P. F.; Dai, S.; McDonough, J.; Presser, V.; Gogotsi, Y., Nanoscale perturbations of room temperature ionic liquid structure at charged and uncharged interfaces. Acs Nano 2012, 6 (11), 9818-9827.

24. Gebbie, M. A.; Valtiner, M.; Banquy, X.; Fox, E. T.; Henderson, W. A.; Israelachvili, J. N., Ionic liquids behave as dilute electrolyte solutions. P. Natl. Acad. Sci. USA 2013, 110 (24), 9674-9679.

25. Zhong, C.; Deng, Y. D.; Hu, W. B.; Qiao, J. L.; Zhang, L.; Zhang, J. J., A review of electrolyte materials and compositions for electrochemical supercapacitors. Chem. Soc. Rev. 2015, 44 (21), 7484-7539.

26. McDonald, S.; Murphy, T.; Imberti, S.; Warr, G. G.; Atkin, R., Amphiphilically nanostructured deep eutectic solvents. J. Phys. Chem. Lett. 2018, 9 (14), 3922-3927.

27. Brown, P.; Butts, C. P.; Eastoe, J.; Fermin, D.; Grillo, I.; Lee, H. C.; Parker, D.; Plana, D.; Richardson, R. M., Anionic surfactant ionic liquids with 1-butyl-3-methyl-imidazolium cations: characterization and application. Langmuir 2012, 28 (5), 2502-2509.

28. Wu, T. Y.; Su, S. G.; Gung, S. T.; Lin, M. W.; Lin, Y. C.; Lai, C. A.; Sun, I. W., Ionic liquids containing an alkyl sulfate group as potential electrolytes. Electrochim. Acta 2010, 55 (15), 4475-4482.

29. Holbrey, J. D.; Reichert, W. M.; Swatloski, R. P.; Broker, G. A.; Pitner, W. R.; Seddon, K. R.; Rogers, R. D., Efficient, halide free synthesis of new, low cost ionic liquids: 1,3dialkylimidazolium salts containing methyl- and ethyl-sulfate anions. Green Chem. 2002, 4 (5), 407-413.

30. Swatloski, R. P.; Holbrey, J. D.; Rogers, R. D., Ionic liquids are not always green: Hydrolysis of 1-butyl-3- methylimidazolium hexafluorophosphate. Green Chem. 2003, 5 (4), 361-363.

31. Canobre, S. C.; Almeida, D. A. L.; Polo Fonseca, C.; Neves, S., Synthesis and characterization of hybrid composites based on carbon nanotubes. Electrochim. Acta 2009, 54 (26), 6383-6388.

32. Khomenko, V.; Raymundo-Piñero, E.; Béguin, F., Optimisation of an asymmetric manganese oxide/activated carbon capacitor working at $2 \mathrm{~V}$ in aqueous medium. J. Power Sources 2006, 153 (1), 183-190.

33. Wu, M.-S.; Lin, K.-H., One-step electrophoretic deposition of Ni-decorated activatedcarbon film as an electrode material for supercapacitors. J. Phys. Chem. C 2010, 114 (13), 6190-6196. 
34. Chidembo, A. T.; Ozoemena, K. I.; Agboola, B. O.; Gupta, V.; Wildgoose, G. G.; Compton, R. G., Nickel(ii) tetra-aminophthalocyanine modified MWCNTs as potential nanocomposite materials for the development of supercapacitors. Energy Environ. Sci. 2010, 3 (2), 228-236. 35. Bhatt, A. I.; May, I.; Volkovich, V. A.; Hetherington, M. E.; Lewin, B.; Thied, R. C.; Ertok, N., Group 15 quaternary alkyl bistriflimides: ionic liquids with potential application in electropositive metal deposition and as supporting electrolytes. J. Chem. Soc., Dalton Trans. 2002, (24), 4532-4534.

36. Cao, Y.; Mu, T., Comprehensive investigation on the thermal stability of 66 ionic liquids by thermogravimetric analysis. Ind. Eng. Chem. Res. 2014, 53 (20), 8651-8664.

37. Simon, P.; Gogotsi, Y., Capacitive energy storage in nanostructured carbon-electrolyte systems. Acc. Chem. Res. 2013, 46 (5), 1094-1103.

38. Pech, D.; Brunet, M.; Durou, H.; Huang, P.; Mochalin, V.; Gogotsi, Y.; Taberna, P.-L.; Simon, P., Ultrahigh-power micrometre-sized supercapacitors based on onion-like carbon. Nat. Nanotechnol. 2010, 5 (9), 651-654.

39. Xie, K.; Qin, X.; Wang, X.; Wang, Y.; Tao, H.; Wu, Q.; Yang, L.; Hu, Z., Carbon nanocages as supercapacitor electrode materials. Adv. Mater. 2012, 24 (3), 347-352.

40. Mao, X.; Yang, X.; Wu, J.; Tian, W.; Rutledge, G. C.; Hatton, T. A., Microwave-assisted oxidation of electrospun turbostratic carbon nanofibers for tailoring energy storage capabilities. Chem. Mater. 2015, 27 (13), 4574-4585.

41. Mao, X.; Simeon, F.; Rutledge, G. C.; Hatton, T. A., Electrospun carbon nanofiber webs with controlled density of states for sensor applications. Adv. Mater. 2013, 25 (9), 1309-1314. 42. Aboutalebi, S. H.; Chidembo, A. T.; Salari, M.; Konstantinov, K.; Wexler, D.; Liu, H. K.; Dou, S. X., Comparison of GO, GO/MWCNTs composite and MWCNTs as potential electrode materials for supercapacitors. Energy Environ. Sci. 2011, 4 (5), 1855-1865.

43. Frackowiak, E.; Jurewicz, K.; Delpeux, S.; Béguin, F., Nanotubular materials for supercapacitors. J. Power Sources 2001, 97-98, 822-825.

44. Frackowiak, E.; Jurewicz, K.; Szostak, K.; Delpeux, S.; Béguin, F., Nanotubular materials as electrodes for supercapacitors. Fuel Process. Technol. 2002, 77-78, 213-219.

45. Frackowiak, E.; Delpeux, S.; Jurewicz, K.; Szostak, K.; Cazorla-Amoros, D.; Béguin, F., Enhanced capacitance of carbon nanotubes through chemical activation. Chem. Phys. Lett. 2002, 361 (1), 35-41.

46. Yuan, W.-L.; Yang, X.; He, L.; Xue, Y.; Qin, S.; Tao, G.-H., Viscosity, Conductivity, and electrochemical property of dicyanamide ionic liquids. Front. Chem. 2018, 6 (59).

47. Welton, T., Ionic liquids: a brief history. Biophys. Rev. 2018, 10 (3), 691-706. 
48. Lin, X.; Salari, M.; Arava, L. M. R.; Ajayan, P. M.; Grinstaff, M. W., High temperature electrical energy storage: advances, challenges, and frontiers. Chem. Soc. Rev. 2016, 45 (21), 5848-5887.

49. Zhong, C.; Deng, Y.; Hu, W.; Qiao, J.; Zhang, L.; Zhang, J., A review of electrolyte materials and compositions for electrochemical supercapacitors. Chem. Soc. Rev. 2015, 44 (21), 7484-7539.

50. Borges, R. S.; Reddy, A. L. M.; Rodrigues, M.-T. F.; Gullapalli, H.; Balakrishnan, K.; Silva, G. G.; Ajayan, P. M., Supercapacitor operating at 200 degrees Celsius. Sci. Rep. 2013, 3 (1), 2572-2578.

51. Simon, P.; Gogotsi, Y., Materials for electrochemical capacitors. Nat. Mater. 2008, 7 (11), $845-854$

52. Mei, B.-A.; Munteshari, O.; Lau, J.; Dunn, B.; Pilon, L., Physical interpretations of nyquist plots for edlc electrodes and devices. J. Phys. Chem. C 2018, 122 (1), 194-206.

53. Taberna, P.; Simon, P.; Fauvarque, J., Electrochemical characteristics and impedance spectroscopy studies of carbon-carbon supercapacitors. J. Electrochem. Soc. 2003, 150, A292A300.

54. Conway, B. E., Introduction and historical perspective. in electrochemical supercapacitors: scientific fundamentals and technological applications, Ed. Springer US: Boston, MA, 1999; pp 1-9.

55. Xu, Y.; Lin, Z.; Zhong, X.; Huang, X.; Weiss, N. O.; Huang, Y.; Duan, X., Holey graphene frameworks for highly efficient capacitive energy storage. Nat. Commun. 2014, 5 (1), 4554.

56. Liu, H.; Zhu, G., The electrochemical capacitance of nanoporous carbons in aqueous and ionic liquids. J. Power Sources 2007, 171, 1054-1061.

57. Balducci, A.; Dugas, R.; Taberna, P. L.; Simon, P.; Plée, D.; Mastragostino, M.; Passerini, S., High temperature carbon-carbon supercapacitor using ionic liquid as electrolyte. J. Power Sources 2007, 165 (2), 922-927.

58. Borges, R.; Ribeiro, H.; Lavall, R.; Silva, G., Temperature stable supercapacitors based on ionic liquid and mixed functionalized carbon nanomaterials. J. Solid State Electrochem. 2012, $16,3573-3580$.

59. Shao, R.; Niu, J.; Liang, J.; Liu, M.; Zhang, Z.; Dou, M.; Huang, Y.; Wang, F., Mesoporeand Macropore-Dominant Nitrogen-Doped Hierarchically Porous Carbons for High-Energy and Ultrafast Supercapacitors in Non-Aqueous Electrolytes. ACS Appl. Mater. Interfaces 2017, 9 (49), 42797-42805. 